Review

\title{
Genetic Susceptibility to Acute Kidney Injury
}

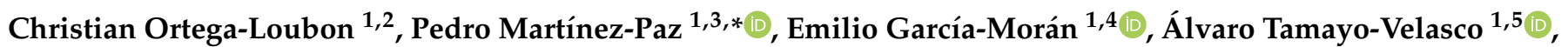 \\ Francisco J. López-Hernández ${ }^{1,6,7}$, Pablo Jorge-Monjas ${ }^{1,8, *}$ and Eduardo Tamayo ${ }^{1,8}$
}

1 BioCritic. Group for Biomedical Research in Critical Care Medicine, University of Valladolid, 47003 Valladolid, Spain; cjortegal@clinic.cat (C.O.-L.); egarmo@egarmo.com (E.G.-M.); alvarotv1993@gmail.com (Á.T.-V.); flopezher@usal.es (F.J.L.-H.); eduardo.tamayo@uva.es (E.T.)

2 Department of Cardiovascular Surgery, Hospital Clinic of Barcelona, 08036 Barcelona, Spain

3 Department of Surgery, Faculty of Medicine, University of Valladolid, 47003 Valladolid, Spain

4 Department of Cardiology, Clinical University Hospital of Valladolid, 47003 Valladolid, Spain

5 Department of Hematology and Hemotherapy, Clinical University Hospital of Valladolid, 47003 Valladolid, Spain

6 Institute of Biomedical Research of Salamnca (IBSAL), University Hospital of Salamanca, 37007 Salamanca, Spain

7 Group of Translational Research on Renal and Cardiovascular Diseases (TRECARD), Departmental Building Campus Miguel de Unamuno, 37007 Salamanca, Spain

8 Department of Anesthesiology and Critical Care, Clinical University Hospital of Valladolid, Ramón y Cajal Ave, 47003 Valladolid, Spain

* Correspondence: pedrojose.martinez@uva.es (P.M.-P.); pablojor@yahoo.es (P.J.-M.); Tel.: +34-9834200000 (P.M.-P.); +34-687978535 (P.J.-M)

check for updates

Citation: Ortega-Loubon, C.; Martínez-Paz, P.; García-Morán, E.; Tamayo-Velasco, Á.;

López-Hernández, F.J.; Jorge-Monjas, P.; Tamayo, E. Genetic Susceptibility to Acute Kidney Injury. J. Clin. Med. 2021, 10, 3039. https://doi.org/ $10.3390 /$ jcm10143039

Academic Editors: Antonio Bellasi and Alberto Martínez-Castelao

Received: 13 May 2021

Accepted: 3 July 2021

Published: 8 July 2021

Publisher's Note: MDPI stays neutral with regard to jurisdictional claims in published maps and institutional affiliations.

Copyright: (c) 2021 by the authors. Licensee MDPI, Basel, Switzerland. This article is an open access article distributed under the terms and conditions of the Creative Commons Attribution (CC BY) license (https:/ / creativecommons.org/licenses/by/ $4.0 /)$.

\begin{abstract}
Acute kidney injury (AKI) is a widely held concern related to a substantial burden of morbidity, mortality and expenditure in the healthcare system. AKI is not a simple illness but a complex conglomeration of syndromes that often occurs as part of other syndromes in its wide clinical spectrum of the disease. Genetic factors have been suggested as potentially responsible for its susceptibility and severity. As there is no current cure nor an effective treatment other than generally accepted supportive measures and renal replacement therapy, updated knowledge of the genetic implications may serve as a strategic tactic to counteract its dire consequences. Further understanding of the genetics that predispose AKI may shed light on novel approaches for the prevention and treatment of this condition. This review attempts to address the role of key genes in the appearance and development of AKI, providing not only a comprehensive update of the intertwined process involved but also identifying specific markers that could serve as precise targets for further AKI therapies.
\end{abstract}

Keywords: acute kidney injury; predisposition; gene polymorphism; genetic variation; intensive care unit

\section{Introduction}

Disparities in kidney disease predisposition among individuals have been sharply identified [1]. The United States Renal Data System Report shows a constant increment in the occurrence of end-stage kidney disease (ESKD) among Africans that is 3.5-5-fold that of Europeans [2]. While the risk of Africans developing ESKD is $8 \%$ approximately, that of Europeans is nearly $2-3 \%$ [3].

\subsection{Acute Kidney Injury}

Acute kidney injury (AKI) is a widely held concern in hospitalized patients [4]. It entails elevated morbidity and mortality [5,6], reaching up to 50-70\% [7], as there are no effective therapies to counteract, ameliorate or speed up the recovery from this condition, other than mainly supportive management [8-14]. Nearly $40 \%$ of patients in intensive care units (ICUs) develop AKI, as well as other concomitant states such as sepsis or 
hemodynamic failure $[15,16]$. AKI is presented by a sharp and unexpected slump in renal function, often related to other medical conditions, such as septic shock, or procedures, for instance cardiac surgery [17]. It is usually defined as a sudden increment in the serum creatinine, a deterioration in renal output or both, occurring within $48 \mathrm{~h}$ or less $[18,19]$. Nevertheless, why certain patients are more vulnerable to develop AKI than others remains unknown [20]. Thus, attempts to promptly identify individuals at risk of getting AKI are of paramount importance, but a reliable prediction of developing AKI remains a challenge.

Despite progress in the comprehension of AKI pathophysiology, its pathogenesis remains complex and incompletely understood [21-23], including numerous pathophysiological mechanisms that lead to sudden tubular necrosis/apoptosis and kidney dysfunction [20,24-26]. These comprise ischemia/reperfusion injury, complement activation, adenosine triphosphate (ATP) reduction, infiltration of leukocytes, generation of endotoxins, oxygen radicals, proinflammatory mediator generation, endothelial damage, fibrosis, microcirculatory dysfunction and, finally, cell death [24,27-29].

Recently, inflammatory response has been recognized as a crucial factor in AKI pathogenesis [25,30-34]. Infiltration of inflammatory cells has been identified in the injured kidney, which causes renal vessel damage and posterior progress to AKI [35]. These cells do not only start but also maintain the kidney damage by producing oxygen radical species, vasoconstrictors such as endothelin and impeding the release of nitric oxide, directly causing endothelial injury [30]. What is more, patients' individual host repair and regeneration biology could also have a major influence on the etiology of AKI [36].

Genetic factors have been proposed as potentially responsible for the susceptibility and severity of AKI, explaining why only particular patients are more prone to AKI and why different patients respond to treatment distinctly [37-41]. This fact has led to a new form of exercise medicine, known as personalized medicine, the aim of which is for patients to be treated as individuals and not as groups [42]. A deeper understanding of how gene interaction drives health or disease might lead to a more personalized medical strategy, allowing the creation of a unique individual genetic print on which medical decisions should be based. Numerous articles have explored the relationship between different polymorphisms and AKI predisposition in various clinical scenarios [43,44]. Table 1 summarizes the evidence related to AKI susceptibility, including the study design, clinical settings, participant/population characteristics, studied polymorphisms and outcomes. 
Table 1. AKI susceptibility studies with their investigated gene polymorphisms along with their related evidence presented chronologically.

\begin{tabular}{|c|c|c|c|c|c|c|c|}
\hline Study & Design & Clinical Settings & $\begin{array}{c}\text { Participants/Population } \\
\text { Characteristics }\end{array}$ & Patients with AKI & $\begin{array}{c}\text { Studied } \\
\text { Polymorphisms }\end{array}$ & Outcomes & AKI Definition \\
\hline $\begin{array}{l}\text { Chew, et al., } \\
2000\end{array}$ & $\begin{array}{l}\text { Prospective, } \\
\text { Observational } \\
\text { Cohort Study }\end{array}$ & CSA-AKI & $\begin{array}{c}564 \text { patients undergoing } \\
\text { CABG } \\
\text { Irish population }\end{array}$ & - & $\begin{array}{c}\text { Apolipoprotein E } \\
\text { (APOE) }\end{array}$ & $\begin{array}{c}\mathrm{APO} 4 \varepsilon 4 \text { allele is } \\
\text { associated with } \\
\text { reduced } \\
\text { postoperative } \\
\text { increase in serum } \mathrm{Cr} \\
\text { after cardiac surgery, } \\
\text { compared with the } \varepsilon 3 \\
\text { or } \varepsilon 2 \text { allele }\end{array}$ & $\begin{array}{c}\text { By comparisons of } \\
\text { preoperative }(\mathrm{CrPre}), \\
\text { peak in-hospital } \\
\text { postoperative } \\
\text { (CrMax) and } \\
\text { perioperative change } \\
(\Delta \mathrm{Cr}) \text { in serum } \mathrm{Cr} \\
\text { values }\end{array}$ \\
\hline $\begin{array}{l}\text { Yu, et al., } \\
2002\end{array}$ & $\begin{array}{l}\text { Case/Control } \\
\text { Study }\end{array}$ & $\begin{array}{l}\text { End-stage renal } \\
\text { disease (ESRD) in } \\
\text { African Americans }\end{array}$ & $\begin{array}{c}85 \text { control subjects, } 92 \\
\text { type } 2 \text { diabetes ESRD } \\
\text { patients, and } 76 \\
\text { non-diabetic ESRD } \\
\text { families. } \\
\text { US population }\end{array}$ & 199 Patients & KLK1 promoter & $\begin{array}{c}\text { KLK1 is associated } \\
\text { with hypertension } \\
\text { ESRD }\end{array}$ & \\
\hline $\begin{array}{c}\text { Jaber, et al., } \\
2004\end{array}$ & Prospective Study & $\begin{array}{l}\text { In-hospital patients } \\
\text { requiring dialysis }\end{array}$ & $\begin{array}{l}\text { Hospitalized patients } \\
\text { who required } \\
\text { intermittent } \\
\text { hemodialysis } \\
\text { England population }\end{array}$ & 61 Patients & TNF- $\alpha$ and IL-10 & $\begin{array}{l}\text { TNF- } \alpha \text { and IL-10 } \\
\text { gene polymorphisms } \\
\text { are related to } \\
\text { increased mortality } \\
\text { among patients with } \\
\text { AKI requiring } \\
\text { dialysis }\end{array}$ & $\begin{array}{l}\text { Renal failure } \\
\text { requiring dialysis }\end{array}$ \\
\hline $\begin{array}{c}\text { Mackensen, et al., } \\
2004\end{array}$ & $\begin{array}{l}\text { Prospective, } \\
\text { Observational } \\
\text { Cohort Study }\end{array}$ & $\begin{array}{l}\text { Elective CABG } \\
\text { patients }\end{array}$ & $\begin{array}{l}130 \text { coronary patients } \\
\text { US population }\end{array}$ & - & $\begin{array}{c}\text { Apolipoprotein E } \\
\text { (APOE) }\end{array}$ & $\begin{array}{c}\text { Non-APOE4 patients } \\
\text { are more vulnerable } \\
\text { to AKI after cardiac } \\
\text { operation } \\
\text { APO4 } \varepsilon 4 \text { allele is } \\
\text { associated with a } \\
\text { nephroprotective } \\
\text { effect }\end{array}$ & $\begin{array}{c}\text { Perioperative } \\
\text { difference in serum } \\
\mathrm{Cr}(\Delta \mathrm{Cr}=\mathrm{Crmax} \\
\text { Post }-\mathrm{Cr} \text { Pre })\end{array}$ \\
\hline
\end{tabular}


Table 1. Cont.

\begin{tabular}{|c|c|c|c|c|c|c|c|}
\hline Study & Design & Clinical Settings & $\begin{array}{c}\text { Participants/Population } \\
\text { Characteristics }\end{array}$ & Patients with AKI & $\begin{array}{c}\text { Studied } \\
\text { Polymorphisms }\end{array}$ & Outcomes & AKI Definition \\
\hline $\begin{array}{l}\text { Stafford-Smith, } \\
\text { et al., } \\
2005\end{array}$ & $\begin{array}{c}\text { Prospective, } \\
\text { longitudinal study }\end{array}$ & CSA-AKI & $\begin{array}{l}3149 \text { patients } \\
\text { undergoing CABG } \\
\text { US population }\end{array}$ & $\begin{array}{l}\text { More than half the } \\
\text { patients }\end{array}$ & $\begin{array}{c}\text { Interleukin } 6 \text {-572C, } \\
\text { AGT } 842 \mathrm{C}, \text { APO E } \\
448 \mathrm{C}[\varepsilon 4], \text { AGTR1 } \\
\text { A1166C, and [eNOS] } \\
894 \mathrm{~T} \\
\text { ACE I/D }\end{array}$ & $\begin{array}{l}\text { AGT } 842 \mathrm{C} \text { and IL-6 } \\
-572 \mathrm{C} \text {, a variant } \\
\text { pattern that occurs in } \\
6 \% \text { of Caucasians) } \\
\text { was associated with } \\
\text { major postoperative } \\
\text { renal injury, with an } \\
\text { average peak serum } \\
\text { Cr increase of } 121 \%\end{array}$ & $\begin{array}{l}\text { Difference between } \\
\text { preoperative and } \\
\text { peak postoperative } \\
\text { Cr values }\end{array}$ \\
\hline $\begin{array}{l}\text { Isbir, et al., } \\
\quad 2007\end{array}$ & $\begin{array}{l}\text { Prospective, } \\
\text { Observational } \\
\text { Cohort Study }\end{array}$ & CSA-AKI & $\begin{array}{l}248 \text { elective CABG } \\
\text { patients } \\
\text { Turkish population }\end{array}$ & 54 Patients & $\begin{array}{l}\text { ACE II, ID, and DD, } \\
\text { APO E, and AGTR1 } \\
\text { A1166C genotype }\end{array}$ & $\begin{array}{l}\text { ACE I/D and APO E } \\
\text { gene polymorphisms } \\
\text { may play a role in the } \\
\text { development of AKI } \\
\text { after cardiac surgery. } \\
\text { AGTR1 does not } \\
\text { have a unique } \\
\text { association with } \\
\text { postoperative AKI }\end{array}$ & RIFLE \\
\hline $\begin{array}{l}\text { Perianayagam, } \\
\text { et al., } \\
2007\end{array}$ & $\begin{array}{c}\text { Prospective Cohort } \\
\text { Study }\end{array}$ & $\begin{array}{c}\text { Hospitalized patients } \\
\text { with AKI }\end{array}$ & $\begin{array}{c}\text { US population } \\
\text { Hospitalized patients } \\
\text { with established AKI of } \\
\text { mixed cause and severity }\end{array}$ & 200 patients & $\begin{array}{l}\text { Coding region }(\mathrm{C} \text { to } \\
\text { T substitution at } \\
\text { position }+242) \\
\text { NADPH oxidase } \\
\text { p22phox subunit } \\
\text { gene and promoter } \\
\text { region }(\mathrm{C} \text { to } \mathrm{T} \\
\text { substitution at } \\
\text { position -262) of the } \\
\text { catalase gene }\end{array}$ & $\begin{array}{l}\text { NADPH oxidase } \\
\text { p22phox subunit at } \\
\text { position }+242 \text { is } \\
\text { associated with } \\
\text { dialysis requirement } \\
\text { or hospital death } \\
\text { among patients with } \\
\text { AKI }\end{array}$ & $\begin{array}{l}\text { An increase in Cr by } \\
0.5,1.0, \text { or } 1.5 \mathrm{mg} / \mathrm{dL} \\
\text { from a baseline level } \\
\text { of } \leq 1.9,2.0 \text { to } 4.9 \\
\text { and } \geq 5.0 \mathrm{mg} / \mathrm{dL}\end{array}$ \\
\hline $\begin{array}{l}\text { Nechemia- Arbely, } \\
\text { et al., } \\
2008\end{array}$ & $\begin{array}{l}\text { Animal Basic } \\
\text { Research }\end{array}$ & $\begin{array}{l}\text { Experimental mice } \\
\text { model }\end{array}$ & $\begin{array}{l}\text { IL-6-deficient mice were } \\
\text { compared with } \\
\text { wild-type mice }\end{array}$ & - & IL-6/sIL-6R & $\begin{array}{c}\text { IL-6 promotes a renal } \\
\text { inflammatory } \\
\text { response }\end{array}$ & $\begin{array}{l}\text { Nephrotoxic- } \\
\text { induced } \\
\text { AKI }\end{array}$ \\
\hline
\end{tabular}


Table 1. Cont.

\begin{tabular}{|c|c|c|c|c|c|c|c|}
\hline Study & Design & Clinical Settings & $\begin{array}{c}\text { Participants/Population } \\
\text { Characteristics }\end{array}$ & Patients with AKI & $\begin{array}{c}\text { Studied } \\
\text { Polymorphisms }\end{array}$ & Outcomes & AKI Definition \\
\hline $\begin{array}{l}\text { Du Cheyron, et al., } \\
2008\end{array}$ & $\begin{array}{c}\text { Prospective Cohort } \\
\text { Study }\end{array}$ & $\begin{array}{l}\text { AKI in ICU admitted } \\
\text { patients }\end{array}$ & $\begin{array}{l}180 \text { ICU patients France } \\
\text { population }\end{array}$ & 73 patients & $\begin{array}{c}\text { ACE I/D } \\
\text { polymorphism }\end{array}$ & $\begin{array}{l}\text { ACE II genotype was } \\
\text { independently } \\
\text { associated with } \\
\text { increased risk of AKI }\end{array}$ & RIFLE \\
\hline $\begin{array}{l}\text { Haase-Fielitz, } \\
\text { et al., } \\
2009\end{array}$ & $\begin{array}{l}\text { Prospective, } \\
\text { observational, } \\
\text { cohort study }\end{array}$ & CSA-AKI & $\begin{array}{l}260 \text { patients undergoing } \\
\text { cardiac surgery } \\
\text { Australian population }\end{array}$ & 53 patients & $\begin{array}{c}\text { Catechol-O- } \\
\text { methyltransferase } \\
(\mathrm{COMT})\end{array}$ & $\begin{array}{c}\text { COMT LL } \\
\text { homozygosity is an } \\
\text { independent risk } \\
\text { factor for AKI }\end{array}$ & RIFLE \\
\hline $\begin{array}{l}\text { Popov, et al., } \\
2009\end{array}$ & Prospective Study & CSA-AKI & $\begin{array}{l}497 \text { patients undergoing } \\
\text { cardiac surgery } \\
\text { German population }\end{array}$ & 287 patients & $\begin{array}{l}\text { T-786C endothelial } \\
\text { NO synthase (eNOS) }\end{array}$ & $\begin{array}{c}\text { T-786C eNOS } \\
\text { polymorphism is } \\
\text { associated with AKI } \\
\text { and increase the } \\
\text { occurrence of RRT } \\
\text { following cardiac } \\
\text { surgery }\end{array}$ & RIFLE \\
\hline $\begin{array}{l}\text { Kolyada, et al., } \\
2009\end{array}$ & $\begin{array}{l}\text { Prospective Cohort } \\
\text { Study }\end{array}$ & $\begin{array}{c}\text { Hospitalized patients } \\
\text { with AKI }\end{array}$ & $\begin{array}{l}\text { Adult patients with AKI } \\
\text { US population }\end{array}$ & 241 patients & $\begin{array}{l}\text { Hypoxia-inducible } \\
\text { factor-1a (HIF-1 } \alpha)\end{array}$ & $\begin{array}{c}\text { HIF-1 } \alpha \text { gene } \\
\text { polymorphism } \\
\text { predicts adverse } \\
\text { outcomes in } \\
\text { hospitalized patients } \\
\text { with AKI }\end{array}$ & AKIN \\
\hline $\begin{array}{c}\text { Alam, et al., } \\
2010\end{array}$ & $\begin{array}{l}\text { Case/Control } \\
\text { Study }\end{array}$ & $\begin{array}{c}\text { Hospitalized patients } \\
\text { with AKI }\end{array}$ & $\begin{array}{l}961 \text { Caucasian subjects } \\
\text { US population }\end{array}$ & 194 Patients & $\begin{array}{c}\text { Phenylethanolamine } \\
\text { N-methyltransferase } \\
\text { (PNMT) } \\
\text { PNMT promoter } \\
\text { G-161A (rs876493) } \\
\text { and coding A + } \\
\text { 1543G (rs5638) }\end{array}$ & $\begin{array}{c}\text { In Caucasians, } \\
\text { PNMT SNPs are } \\
\text { associated with the } \\
\text { development of AKI, } \\
\text { disease severity, and } \\
\text { in-hospital mortality }\end{array}$ & AKIN \\
\hline
\end{tabular}


Table 1. Cont.

\begin{tabular}{|c|c|c|c|c|c|c|c|}
\hline Study & Design & Clinical Settings & $\begin{array}{c}\text { Participants/Population } \\
\text { Characteristics }\end{array}$ & Patients with AKI & $\begin{array}{c}\text { Studied } \\
\text { Polymorphisms }\end{array}$ & Outcomes & AKI Definition \\
\hline $\begin{array}{l}\text { Popov, et al., } \\
2010\end{array}$ & $\begin{array}{c}\text { Prospective Cohort } \\
\text { Study }\end{array}$ & CSA-AKI & $\begin{array}{l}481 \text { Patients undergoing } \\
\text { Cardiac Surgery } \\
\text { German population }\end{array}$ & 274 Patients & $\begin{array}{l}\text { SNP rs } 1617640 \text { in the } \\
\text { promoter of the EPO } \\
\text { gene }\end{array}$ & $\begin{array}{c}\text { EPO rs1617460 TT } \\
\text { allele is associated } \\
\text { with more acute RRT }\end{array}$ & RIFLE \\
\hline $\begin{array}{l}\text { Perianayagam, } \\
\text { et al., } \\
2011\end{array}$ & $\begin{array}{l}\text { Prospective, } \\
\text { Observational } \\
\text { Cohort Study }\end{array}$ & $\begin{array}{l}\text { Hospitalized adults } \\
\text { with AKI }\end{array}$ & $\begin{array}{l}256 \text { hospitalized patients } \\
\text { US population }\end{array}$ & 256 Patients & $\begin{array}{l}\text { CYBA gene } \\
\text { polymorphisms } \\
\text { (rs8854, rs3794624, } \\
\text { rs4673, rs4782390, } \\
\text { and rs1049255) }\end{array}$ & $\begin{array}{c}\text { CYBA rs4782390, } \\
\text { rs4673, rs3794624, } \\
\text { and rs8854 } \\
\text { polymorphisms were } \\
\text { associated with } \\
\text { dialysis requirement }\end{array}$ & $\begin{array}{c}\text { A rise in serum Cr by } \\
0.5,1.0, \text { or } 1.5 \mathrm{mg} / \mathrm{dL} \\
\text { from a baseline level } \\
\leq 1.9,2.0-4.9, \text { or } \geq 5.0 \\
\mathrm{mg} / \mathrm{dL}\end{array}$ \\
\hline $\begin{array}{l}\text { Jouan, et al., } \\
2012\end{array}$ & $\begin{array}{c}\text { Prospective Cohort } \\
\text { Study }\end{array}$ & CSA-AKI & $\begin{array}{c}126 \text { Patients undergoing } \\
\text { CABG } \\
\text { France population }\end{array}$ & 8 Patients & $\begin{array}{c}\text { LTA } \\
\text { (Cys13Arg,p252A > } \\
\text { G), TNF- } \alpha(-308 G> \\
\text { A), IL6 }(-597 \mathrm{G}>\mathrm{A}, \\
-572 \mathrm{G}>\mathrm{C},-174 \mathrm{G}> \\
\text { C), IL10 }(-592 \mathrm{C}>\mathrm{A}, \\
\left.\text { c. }{ }^{*} 117 \mathrm{C}>\mathrm{T}\right), \text { and } \\
\text { APOE (Cys112Arg, } \\
\text { Arg158Cys). }\end{array}$ & $\begin{array}{c}\text { IL6- } \\
\text { 572GCpCC/IL10- } \\
\text { 592CC were } \\
\text { associated with AKI }\end{array}$ & $\begin{array}{c}\text { As Cr levels }>200 \\
\text { mmol/L or, } \\
\text { particularly for } \\
\text { patients having a } \\
\text { baseline plasma Cr } \\
\text { level }>150 \mathrm{mmol} / \mathrm{L} \text {, } \\
\text { the requirement for } \\
\text { dialysis at any time } \\
\text { after surgery. }\end{array}$ \\
\hline $\begin{array}{l}\text { Cardinal- } \\
\text { Fernandez, et al., } \\
2012\end{array}$ & Systematic Review & $\begin{array}{c}\text { Genetic } \\
\text { Predisposition to AKI }\end{array}$ & 4.835 patients included & 12 References & $\begin{array}{c}\text { ACE, eNOS, FNMT y } \\
\text { COMT, TNF- } \alpha, \text { IL10, } \\
\text { IL6, HIP-1A, EPO, } \\
\text { NAPH oxidase, and } \\
\text { APOE }\end{array}$ & $\begin{array}{l}\text { AKI susceptibility } \\
\text { and severity is } \\
\text { related to genetic } \\
\text { factors that are } \\
\text { involved in different } \\
\text { physiopathological } \\
\text { mechanisms }\end{array}$ & AKI term search \\
\hline $\begin{array}{c}\text { Susantitaphong, } \\
\text { et al., } \\
2012\end{array}$ & $\begin{array}{l}\text { Case/Control } \\
\text { Study }\end{array}$ & $\begin{array}{l}\text { Hospitalized cases } \\
\text { with AKI of multiple } \\
\text { etiology from two } \\
\text { acute care facilities }\end{array}$ & $\begin{array}{c}481 \text { subjects ( } 214 \\
\text { hospitalized patients } \\
\text { with AKI of mixed } \\
\text { causes and } 267 \text { healthy } \\
\text { subjects) }\end{array}$ & 214 Patients & $\begin{array}{l}\text { Multiallelic KLK1 } \\
\text { promoter gene }\end{array}$ & $\begin{array}{l}\text { KLK1 promoter } \\
\text { polymorphisms are } \\
\text { associated with } \\
\text { development of AKI } \\
\text { and adverse } \\
\text { outcomes }\end{array}$ & AKIN \\
\hline
\end{tabular}


Table 1. Cont.

\begin{tabular}{|c|c|c|c|c|c|c|c|}
\hline Study & Design & Clinical Settings & $\begin{array}{c}\text { Participants/Population } \\
\text { Characteristics }\end{array}$ & Patients with AKI & $\begin{array}{c}\text { Studied } \\
\text { Polymorphisms }\end{array}$ & Outcomes & AKI Definition \\
\hline $\begin{array}{l}\text { Perianayagam, } \\
\text { et al., } \\
2012\end{array}$ & $\begin{array}{l}\text { Prospective Cohort } \\
\text { Study }\end{array}$ & $\begin{array}{l}\text { Hospitalized patients } \\
\text { with AKI }\end{array}$ & $\begin{array}{l}262 \text { adults hospitalized } \\
\text { with acute kidney injury }\end{array}$ & 262 Patients & $\begin{array}{c}\text { MPO } \\
\text { polymorphisms } \\
\text { rs2243828, rs7208693, } \\
\text { rs2071409, and rs2759 }\end{array}$ & $\begin{array}{c}\text { MPO } \\
\text { polymorphisms } \\
\text { rs2243828, rs7208693, } \\
\text { rs2071409, and rs2759 } \\
\text { were associated with } \\
\text { lower urine output, } \\
\text { more dialysis } \\
\text { requirement and } \\
\text { higher in-hospital } \\
\text { mortality. }\end{array}$ & AKIN \\
\hline $\begin{array}{l}\text { Payen, et al., } \\
2012\end{array}$ & $\begin{array}{c}\text { Prospective } \\
\text { multicenter } \\
\text { observational study }\end{array}$ & $\begin{array}{l}\text { Critical ill patients } \\
\text { with severe sepsis } \\
\text { and septic shock }\end{array}$ & $\begin{array}{l}221 \text { Patients } \\
\text { France population }\end{array}$ & 129 Patients & HLA-DRB1 & $\begin{array}{l}\text { HLA-DRB alleles } \\
\text { were found to be } \\
\text { associated with less } \\
\text { requirement of RRT }\end{array}$ & AKIN \\
\hline $\begin{array}{c}\text { Frank, et al., } \\
2012\end{array}$ & $\begin{array}{l}\text { Retrospective } \\
\text { Study }\end{array}$ & $\begin{array}{l}\text { AKI in Patients with } \\
\text { septic shock }\end{array}$ & $\begin{array}{l}\text { 1,264 patients with septic } \\
\text { shock }\end{array}$ & 637 Patients & $\begin{array}{c}\text { BCL2 Genetic } \\
\text { Variants SERPINA4 } \\
\text { SNP rs2093266 }\end{array}$ & $\begin{array}{c}\text { BCL2 SNPs } \\
\text { rs8094315 and } \\
\text { rs12457893 were } \\
\text { associated with a } \\
\text { decreased risk of } \\
\text { developing AKI } \\
\text { SERPINA4 SNP } \\
\text { rs2093266 was linked } \\
\text { to a decreased risk to } \\
\text { develop AKI }\end{array}$ & AKIN \\
\hline
\end{tabular}


Table 1. Cont.

\begin{tabular}{|c|c|c|c|c|c|c|c|}
\hline Study & Design & Clinical Settings & $\begin{array}{c}\text { Participants/Population } \\
\text { Characteristics }\end{array}$ & Patients with AKI & $\begin{array}{c}\text { Studied } \\
\text { Polymorphisms }\end{array}$ & Outcomes & AKI Definition \\
\hline $\begin{array}{l}\text { Jin, et al., } \\
2013\end{array}$ & $\begin{array}{l}\text { Animal Basic } \\
\text { Research }\end{array}$ & $\begin{array}{l}\text { Mouse Model of } \\
\text { Ischemic- } \\
\text { Reperfusion } \\
\text { Injury }\end{array}$ & $\begin{array}{c}\text { Wild-type mice, } \\
\text { compared to adiponectin } \\
\text { knockout mice }\end{array}$ & - & Adiponection & $\begin{array}{c}\text { Adiponectin } \\
\text { wild-type mice had } \\
\text { less kidney } \\
\text { dysfunction and } \\
\text { tubular damage. } \\
\text { There was more } \\
\text { inhibition of NF-kB } \\
\text { activation and } \\
\text { reduced expression } \\
\text { of the } \\
\text { proinflammatory } \\
\text { molecules IL-6, } \\
\text { TNF- } \alpha, \text { MCP-1, and } \\
\text { MIP-2 }\end{array}$ & $\begin{array}{l}\text { Ischemic- } \\
\text { Reperfusion } \\
\text { Injury }\end{array}$ \\
\hline $\begin{array}{l}\text { Cardinal- } \\
\text { Fernández, et al., } \\
2013\end{array}$ & $\begin{array}{l}\text { Prospective, } \\
\text { observational, } \\
\text { cohort study }\end{array}$ & $\begin{array}{l}\text { Patients admitted to } \\
\text { the ICU with severe } \\
\text { sepsis }\end{array}$ & $\begin{array}{l}139 \text { Patients with severe } \\
\text { sepsis }\end{array}$ & 65 patients & $\begin{array}{c}\text { Angiotensin- } \\
\text { converting enzyme } \\
\text { insertion/deletion; } \\
\text { tumor necrosis factor } \\
\alpha-376,-308 \text {, and } \\
\text {-238; interleukin-8 } \\
-251 ; \text { vascular } \\
\text { endothelial growth } \\
\text { factor (VEGF) +405 } \\
\text { and +936; and } \\
\text { pre-B-cell } \\
\text { colony-enhancing } \\
\text { factor -1001 }\end{array}$ & $\begin{array}{l}\text { VEGF + 936 CC } \\
\text { genotype increased } \\
\text { the risk to develop } \\
\text { AKI in patients with } \\
\text { severe sepsis. }\end{array}$ & RIFLE \\
\hline
\end{tabular}


Table 1. Cont.

\begin{tabular}{|c|c|c|c|c|c|c|c|}
\hline Study & Design & Clinical Settings & $\begin{array}{c}\text { Participants/Population } \\
\text { Characteristics }\end{array}$ & Patients with AKI & $\begin{array}{c}\text { Studied } \\
\text { Polymorphisms }\end{array}$ & Outcomes & AKI Definition \\
\hline $\begin{array}{c}\text { McBride, et al., } \\
2013\end{array}$ & $\begin{array}{l}\text { Prospective, } \\
\text { observational, } \\
\text { cohort study }\end{array}$ & CSA-AKI & $\begin{array}{l}408 \text { elective cardiac } \\
\text { surgery patients } \\
\text { Irish population }\end{array}$ & 69 Patients & $\begin{array}{c}\text { TNF/G-308A, TGF- } \beta \\
\text { 1-509 C/T, } \\
\text { IL10/G-1082A and } \\
\text { ACE I/D. }\end{array}$ & $\begin{array}{c}\text { TNF/G-308A, TGF- } \beta \\
1-509 \text { C/T, } \\
\text { IL10/G-1082A and } \\
\text { ACE I/D. genotype } \\
\text { were not associated } \\
\text { with AKI }\end{array}$ & $\begin{array}{l}\text { Drop from baseline } \\
\text { eGFR of greater than } \\
25 \% \text { (as calculated by } \\
\text { the method of } \\
\text { MDRD. }\end{array}$ \\
\hline $\begin{array}{l}\text { Susantitaphong, } \\
\text { et al., } \\
2013\end{array}$ & Cohort Study & $\begin{array}{l}\text { Hospitalized patients } \\
\text { with AKI were } \\
\text { recruited from two } \\
\text { acute care hospitals }\end{array}$ & $\begin{array}{c}262 \text { hospitalized German } \\
\text { population }\end{array}$ & 262 Patients & $\begin{array}{c}\text { Promoter region of } \\
\text { TNF- } \alpha\end{array}$ & $\begin{array}{l}\text { The TNF- } \alpha \text { rs } 1800629 \\
\text { gene polymorphism } \\
\text { is associated with } \\
\text { markers of kidney } \\
\text { disease severity and } \\
\text { distant organ } \\
\text { dysfunction among } \\
\text { patients with AKI }\end{array}$ & $\begin{array}{l}\text { A rise in serum Cr by } \\
0.5,1.0, \text { or } 1.5 \mathrm{mg} / \mathrm{dL} \\
\text { from a baseline level } \\
\text { of } \leq 1.9,2.0-4.9, \text { or } \\
\quad \geq 5.0 \mathrm{mg} / \mathrm{dL}\end{array}$ \\
\hline $\begin{array}{l}\text { Chang, et al., } \\
2013\end{array}$ & $\begin{array}{l}\text { Prospective } \\
\text { Case/Control } \\
\text { Study }\end{array}$ & $\begin{array}{l}\text { Patients who } \\
\text { underwent coronary } \\
\text { artery intervention }\end{array}$ & $\begin{array}{l}53 \text { contrast induced-AKI } \\
\text { patients compared to } 455 \\
\text { control subjects. }\end{array}$ & $\begin{array}{c}53 \text { contrast } \\
\text { induced-AKI patients }\end{array}$ & $\begin{array}{l}\text { Four IL-10 tag SNPs } \\
\text { (rs1554286, rs3021094, } \\
\text { rs3790622, rs1800896) } \\
\text { and three TNF- } \alpha \text { tag } \\
\text { SNPs (rs1799964, } \\
\text { rs1800630, rs1800629) }\end{array}$ & $\begin{array}{c}\text { Gene polymorphisms } \\
\text { of IL-10 and TNF- } \alpha \\
\text { are associated with } \\
\text { Contrast } \\
\text { induced-AKI }\end{array}$ & $\begin{array}{c}\text { A rise in } \mathrm{Cr} \text { of } \geq 0.5 \\
\mathrm{mg} / \mathrm{dL}(44 \mathrm{mmol} / \mathrm{L}) \\
\text { or a } 25 \% \text { increase } \\
\text { from baseline value, } \\
\text { assessed within } 48 \mathrm{~h} \\
\text { after a radiological } \\
\text { procedure }\end{array}$ \\
\hline $\begin{array}{c}\text { Kornet, et al., } \\
2013\end{array}$ & $\begin{array}{l}\text { Prospective, } \\
\text { Observational } \\
\text { Cohort Study }\end{array}$ & CSA-AKI & $\begin{array}{l}1741 \text { patients undergoing } \\
\text { elective cardiac surgery } \\
\text { German population }\end{array}$ & 398 Patients & $\begin{array}{l}\text { COMT-Val158Met- } \\
\text { (G/A) } \\
\text { polymorphism } \\
\text { (rs4680) }\end{array}$ & $\begin{array}{l}\text { COMT-Val158Met- } \\
\text { (G/A) } \\
\text { polymorphism } \\
\text { (rs4680) was not } \\
\text { associated with } \\
\text { CSA-AKI }\end{array}$ & RIFLE \\
\hline
\end{tabular}


Table 1. Cont.

\begin{tabular}{|c|c|c|c|c|c|c|c|}
\hline Study & Design & Clinical Settings & $\begin{array}{c}\text { Participants/Population } \\
\text { Characteristics }\end{array}$ & Patients with AKI & $\begin{array}{c}\text { Studied } \\
\text { Polymorphisms }\end{array}$ & Outcomes & AKI Definition \\
\hline $\begin{array}{l}\text { Dalboni, et al., } \\
2013\end{array}$ & $\begin{array}{l}\text { Prospective nested } \\
\text { case-control }\end{array}$ & ICU Setting & $\begin{array}{l}303 \text { ICU patients and } 244 \\
\text { healthy individuals }\end{array}$ & 139 Patients & $\begin{array}{c}-308 \mathrm{G}<\mathrm{A}(\mathrm{TNF})-\alpha \\
-174 \mathrm{G}>\mathrm{C} \text { IL-6 and } \\
-1082 \mathrm{G}>\mathrm{A} \text { IL-10 }\end{array}$ & $\begin{array}{l}\text { Both low TNF- } \alpha \text { and } \\
\text { low IL-10 producer } \\
\text { phenotypes were an } \\
\text { independent risk } \\
\text { factor of AKI and/or } \\
\text { death and RRT } \\
\text { and/or death in ICU } \\
\text { patients. }\end{array}$ & AKIN, and RIFLE \\
\hline $\begin{array}{l}\text { Lipkowitz, et al., } \\
2013\end{array}$ & $\begin{array}{l}\text { Case/Control } \\
\text { Study }\end{array}$ & $\begin{array}{c}\text { Hypertension- } \\
\text { attributed } \\
\text { nephropathy who } \\
\text { developed severe } \\
\text { CKD }\end{array}$ & $\begin{array}{c}675 \text { Cases compared to } \\
618 \text { Controls } \\
\text { African Americans }\end{array}$ & 675 Patients & $\begin{array}{l}\text { APOL1 and MYH9 } \\
\text { genes }\end{array}$ & $\begin{array}{l}\text { APOL1 risk variants } \\
\text { were consistently } \\
\text { associated with renal } \\
\text { disease progression }\end{array}$ & $\begin{array}{c}\text { (1) Developing ESRD } \\
\text { or } \mathrm{Cr}>2 \mathrm{mg} / \mathrm{mL} \text {; }(2) \\
\text { developing ESKD or } \\
\mathrm{Cr}>3 \mathrm{mg} / \mathrm{dL}\end{array}$ \\
\hline $\begin{array}{l}\text { Parsa, et al., } \\
2013\end{array}$ & $\begin{array}{c}\text { AASK and CRIC } \\
\text { Study } \\
\text { Cohort Study }\end{array}$ & $\begin{array}{l}\text { Black patients in the } \\
\text { United States with } \\
\text { chronic kidney } \\
\text { disease } \\
\text { US Population }\end{array}$ & $\begin{array}{c}\text { AASK: } 693 \text { black patients } \\
\text { with chronic kidney } \\
\text { disease attributed to } \\
\text { hypertension } \\
\text { CRIC: } 2955 \text { white } \\
\text { patients and black } \\
\text { patients with chronic } \\
\text { kidney disease }\end{array}$ & $\begin{array}{l}492 \text { Patients in the } \\
\text { AASK Study }\end{array}$ & APOL1 & $\begin{array}{c}\text { APOL1 were } \\
\text { associated with the } \\
\text { higher rates of } \\
\text { end-stage renal } \\
\text { disease and } \\
\text { progression of CKD } \\
\text { that were observed in } \\
\text { black patients as } \\
\text { compared with white } \\
\text { patients }\end{array}$ & $\begin{array}{l}\text { A doubling of the } \mathrm{Cr} \\
\text { (equivalent to a } \\
\text { reduction of } 50 \% \text { in } \\
\text { the GFR) from } \\
\text { baseline or incident } \\
\text { ESRD }\end{array}$ \\
\hline $\begin{array}{l}\text { Henao-Martínez, } \\
\text { et al., } \\
2013\end{array}$ & $\begin{array}{l}\text { Prospective, } \\
\text { Observational } \\
\text { Cohort Study }\end{array}$ & AKI in sepsis & 250 hospitalized patients & 159 Patients & SUFU & $\begin{array}{c}\text { rs10786691 }(p=0.03) \\
\text { rs12414407 }(p= \\
0.026), \text { rs10748825 }(p \\
=0.01), \text { and } \\
\text { rs7078511 correlated } \\
\text { to AKI }\end{array}$ & Based on Serum Cr \\
\hline
\end{tabular}


Table 1. Cont.

\begin{tabular}{|c|c|c|c|c|c|c|c|}
\hline Study & Design & Clinical Settings & $\begin{array}{c}\text { Participants/Population } \\
\text { Characteristics }\end{array}$ & Patients with AKI & $\begin{array}{c}\text { Studied } \\
\text { Polymorphisms }\end{array}$ & Outcomes & AKI Definition \\
\hline $\begin{array}{c}\text { Boehm, et al., } \\
2014\end{array}$ & $\begin{array}{l}\text { Prospective, } \\
\text { Observational } \\
\text { Cohort Study }\end{array}$ & CSA-AKI & $\begin{array}{l}1415 \text { elective cardiac } \\
\text { surgery patients } \\
\text { German population }\end{array}$ & 318 Patients & $\begin{array}{c}\text { Apolipoprotein E } \\
\text { (ApoE } \varepsilon 2, \varepsilon 3, \varepsilon 4) \\
\text { (rs429358 and rs7412) } \\
\text { and TNF- } \alpha-308 \mathrm{G}> \\
\text { A (rs1800629). }\end{array}$ & $\begin{array}{c}\text { ApoE }(\varepsilon 2, \varepsilon 3, \varepsilon 4) \\
\text { polymorphism and } \\
\text { the TNF- } \alpha-308 \mathrm{G}>\mathrm{A} \\
\text { polymorphism are } \\
\text { not associated with } \\
\text { CSA-AKI }\end{array}$ & RIFLE \\
\hline $\begin{array}{c}\text { Grabulosa, et al., } \\
2014\end{array}$ & $\begin{array}{l}\text { Prospective nested } \\
\text { case-control study }\end{array}$ & ICU patients & $\begin{array}{l}139 \text { ICU AKI patients, } \\
164 \text { ICU patients without } \\
\text { AKI, compared to } 244 \\
\text { healthy individuals. }\end{array}$ & 139 Patients & $\begin{array}{l}\text { rs1800470 (codon } 10 \\
\mathrm{~T} / \mathrm{C}), \text { rs } 1800471 \\
\text { (codon } 25 \mathrm{C} / \mathrm{G}) \text { from } \\
\text { the TGF- } \beta \text {, and } \\
\text { rs } 2430561(+874 \mathrm{~T} / \mathrm{A}) \\
\text { from IFN- } \gamma\end{array}$ & $\begin{array}{c}\text { Genetic } \\
\text { polymorphism of the } \\
\text { TGF- } \beta \text { and IFN- } \gamma \\
\text { was not associated as } \\
\text { a risk factor for AKI }\end{array}$ & AKIN, RIFLE \\
\hline $\begin{array}{l}\text { Albert, et al., } \\
2014\end{array}$ & $\begin{array}{l}\text { Prospective, } \\
\text { Observational } \\
\text { Cohort Study }\end{array}$ & CSA-AKI & $\begin{array}{l}195 \text { patients } \\
\text { German Cohort }\end{array}$ & 22 Patients & COMT-Val158Met & $\begin{array}{l}\text { COMT genotype may } \\
\text { associate with } \\
\text { different patterns of } \\
\text { renal functional } \\
\text { changes and tubular } \\
\text { stress biomarker } \\
\text { response after } \\
\text { cardiac surgery. }\end{array}$ & RIFLE \\
\hline $\begin{array}{l}\text { Lin, et al., } \\
\quad 2015\end{array}$ & Systematic Review & AKI & $\begin{array}{c}11 \text { References from } 3 \\
\text { countries } \\
2796 \text { patients }\end{array}$ & 538 patients & IL-18 & $\begin{array}{l}\text { IL-18 could be used } \\
\text { as a biomarker in the } \\
\text { prediction of AKI }\end{array}$ & $\begin{array}{l}\text { RIFLE, AKIN, } \\
\text { pRIFLE }\end{array}$ \\
\hline $\begin{array}{c}\text { Stafford-Smith, } \\
2015\end{array}$ & GWAS & AKI following CAGB & $\begin{array}{c}873 \text { non-emergent CABG } \\
\text { patients (discovery) } \\
380 \text { cardiac surgery } \\
\text { patients (replication) } \\
\text { US population }\end{array}$ & $\begin{array}{l}294 \text { in Discovery } \\
\text { Cohort } \\
119 \text { in Replication } \\
\text { Cohort }\end{array}$ & $\begin{array}{c}\text { The rs13317787 in } \\
\text { GRM7 I LMCD1-AS1 } \\
\text { intergenic region } \\
\text { (3p21.6) and } \\
\text { rs10262995 in BBS9 } \\
(7 \mathrm{p} 14.3)\end{array}$ & $\begin{array}{l}\text { GRM7 I LMCD1-AS1 } \\
\text { and BBS9 were } \\
\text { associated with } \\
\text { post-CABG AKI }\end{array}$ & $\begin{array}{l}\text { KDIGO, AKIN, } \\
\text { RIFLE }\end{array}$ \\
\hline
\end{tabular}


Table 1. Cont.

\begin{tabular}{|c|c|c|c|c|c|c|c|}
\hline Study & Design & Clinical Settings & $\begin{array}{c}\text { Participants/Population } \\
\text { Characteristics }\end{array}$ & Patients with AKI & $\begin{array}{c}\text { Studied } \\
\text { Polymorphisms }\end{array}$ & Outcomes & AKI Definition \\
\hline $\begin{array}{l}\text { Greenberg, et al., } \\
2015\end{array}$ & Prospective Study & $\begin{array}{l}\text { Pediatric Cardiac } \\
\text { Surgery }\end{array}$ & $\begin{array}{l}\text { Cohort, including } 106 \\
\text { children ranging in age } \\
\text { from } 1 \text { month to } 18 \text { years } \\
\text { undergoing CPB }\end{array}$ & 24 Patients & IL-6 and IL-10 & $\begin{array}{l}\text { Preoperative plasma } \\
\text { IL-6 levels are } \\
\text { associated with AKI }\end{array}$ & $\begin{array}{l}\text { At least a doubling of } \\
\text { the baseline } \mathrm{Cr} \\
\text { concentration or } \\
\text { dialysis }\end{array}$ \\
\hline $\begin{array}{l}\text { Vilander, et al., } \\
\qquad 2015\end{array}$ & Systematic Review & $\begin{array}{l}\text { Genetic } \\
\text { predisposition to AKI }\end{array}$ & 4027 References & 28 References & $\begin{array}{c}\text { ACE; AGTR1; AGT; } \\
\text { APOE; BCL-2; } \\
\text { COMT; CYBA; eNOS; } \\
\text { EPO; FCGR2A; } \\
\text { FCGR3A; FCGR3B; } \\
\text { GLI1; HHIP; HIF-1- } \\
\alpha \text {; HLA-DRB1; IL-6; } \\
\text { IL-8; IL-10; LTA; } \\
\text { MPO; NADPH; } \\
\text { PBEF; PNMT; } \\
\text { PTCH1; PTCH2; } \\
\text { SERPINA4; } \\
\text { SERPINA5; SIK3; } \\
\text { SMO; SUFU; TGF- } \beta ; \\
\text { TNF- } \alpha \text {; VEGF. }\end{array}$ & $\begin{array}{l}\text { Articles quite } \\
\text { heterogeneous and of } \\
\text { moderate quality }\end{array}$ & $\begin{array}{l}\text { KDIGO, AKIN, } \\
\text { RIFLE }\end{array}$ \\
\hline $\begin{array}{l}\text { Kidir, et al., } \\
2016\end{array}$ & $\begin{array}{l}\text { Cross-sectional } \\
\text { Study }\end{array}$ & $\begin{array}{l}\text { Case (AKI)/Control } \\
\text { Hospitalized patients }\end{array}$ & $\begin{array}{l}\text { Turkish population } 90 \\
\text { AKI patients compared } \\
\text { to } 101 \text { healthy volunteers }\end{array}$ & 90 AKI patients & $\begin{array}{l}\text { MnSOD rs4880, } \\
\text { GPX1 rs10500450 and } \\
\text { CAT rs769217 }\end{array}$ & $\begin{array}{c}\text { T allele of CAT } \\
\text { rs769217 was } \\
\text { associated with } \\
\text { increased morbidity } \\
\text { and mortality }\end{array}$ & KDIGO \\
\hline
\end{tabular}


Table 1. Cont.

\begin{tabular}{|c|c|c|c|c|c|c|c|}
\hline Study & Design & Clinical Settings & $\begin{array}{l}\text { Participants/Population } \\
\text { Characteristics }\end{array}$ & Patients with AKI & $\begin{array}{c}\text { Studied } \\
\text { Polymorphisms }\end{array}$ & Outcomes & AKI Definition \\
\hline $\begin{array}{c}\text { Zhao, et al., } \\
2017\end{array}$ & GWAS & $\begin{array}{l}\text { Cases and controls } \\
\text { for the discovery } \\
\text { population were } \\
\text { derived from two } \\
\text { independent } \\
\text { populations of } \\
\text { critically ill patients. } \\
\text { The second } \\
\text { population enrolled } \\
\text { patients who } \\
\text { underwent cardiac } \\
\text { surgery }\end{array}$ & $\begin{array}{l}\text { Discovery population: } \\
760 \text { acute kidney injury } \\
\text { cases and } 669 \text { controls. } \\
\text { Replication population: } \\
206 \text { cases and } 1406 \\
\text { Controls }\end{array}$ & $\begin{array}{l}760 \text { patients } \\
\text { (Discovery) and } 206 \\
\text { (Replication) }\end{array}$ & $\begin{array}{l}\text { APOL1-regulator } \\
\text { IRF2 and } \\
\text { AKI-related TBX1 } \\
\text { genes }\end{array}$ & $\begin{array}{c}\text { rs62341639 and } \\
\text { rs62341657 on } \\
\text { chromosome } 4 \text { near } \\
\text { APOL1-regulator } \\
\text { IRF2, and rs9617814 } \\
\text { and rs10854554 on } \\
\text { chromosome } 22 \text { near } \\
\text { acute kidney } \\
\text { injury-related gene } \\
\text { TBX1 are associated } \\
\text { with AKI }\end{array}$ & $\begin{array}{l}\text { At least } 0.3-\mathrm{mg} / \mathrm{dL} \\
\text { or } 50 \% \text { increase in } \mathrm{Cr} \\
\text { from baseline }\end{array}$ \\
\hline $\begin{array}{c}\text { Johnson, et al., } \\
2017\end{array}$ & $\begin{array}{l}\text { Animal Basic } \\
\text { Research }\end{array}$ & $\begin{array}{l}\text { Experimental mice } \\
\text { model }\end{array}$ & 74 male Wistar rats & 74 mice & $\begin{array}{l}\text { Nuclear factor-kB } \\
\text { (NFkB) }\end{array}$ & $\begin{array}{c}\text { Inhibition IкB kinase } \\
\text { improves kidney } \\
\text { recovery and } \\
\text { decreases fibrosis }\end{array}$ & $\begin{array}{l}\text { AKI caused by } \\
\text { unilateral } \\
\text { nephrectomy plus } \\
\text { contralateral } \\
\text { ischemia and } \\
\text { reperfusion injury }\end{array}$ \\
\hline $\begin{array}{c}\text { Hashad, et al., } \\
2017\end{array}$ & $\begin{array}{c}\text { Prospective Cohort } \\
\text { Study }\end{array}$ & $\begin{array}{l}\text { Critical ill patients } \\
\text { with severe sepsis }\end{array}$ & $\begin{array}{l}150 \text { patients with severe } \\
\text { sepsis }\end{array}$ & 66 patients & $\begin{array}{c}-398 \mathrm{G} / \mathrm{C} \text { of TNF- } \alpha \\
\text { and }-1082 \mathrm{G} / \mathrm{A} \text { of } \\
\text { IL-10 }\end{array}$ & $\begin{array}{c}\text { Genotypes of both } \\
\text { TNF- } \alpha \text { and IL-10 } \\
\text { were associated with } \\
\text { AKI }\end{array}$ & - \\
\hline $\begin{array}{l}\text { Liu, et al., } \\
\quad 2017\end{array}$ & $\begin{array}{l}\text { Case/Control } \\
\text { Study }\end{array}$ & $\begin{array}{l}\text { AKI in ICU Chinese } \\
\text { population }\end{array}$ & $\begin{array}{l}159 \text { AKI patients ( } 88 \\
\text { female and } 71 \text { male) } \\
\text { admitted in ICU } \\
\text { compared to } 120 \\
\text { age-matched healthy } \\
\text { volunteers (50 female } \\
\text { and } 70 \text { male) }\end{array}$ & 159 patients & $\begin{array}{c}\text { SP-D polymorphism } \\
\text { Thr11Met and } \\
\text { Thr160Ala }\end{array}$ & $\begin{array}{l}\text { SP-D-Thr11Met } \\
\text { genotype was more } \\
\text { susceptible to AKI }\end{array}$ & KDIGO \\
\hline
\end{tabular}


Table 1. Cont.

\begin{tabular}{|c|c|c|c|c|c|c|c|}
\hline Study & Design & Clinical Settings & $\begin{array}{c}\text { Participants/Population } \\
\text { Characteristics }\end{array}$ & Patients with AKI & $\begin{array}{c}\text { Studied } \\
\text { Polymorphisms }\end{array}$ & Outcomes & AKI Definition \\
\hline $\begin{array}{c}\text { Fatani, et al., } \\
2018\end{array}$ & Prospective Study & $\begin{array}{l}\text { Critical ill patients } \\
\text { Severe sepsis } \\
\text { induced AKI }\end{array}$ & $\begin{array}{l}200 \text { critically-ill patients } \\
\text { (112 had severe sepsis } \\
\text { and septic shock and } 88 \\
\text { were septic) }\end{array}$ & 127 patients & TNF- $\alpha$ rs 361525 & $\begin{array}{l}\text { TNF- } \alpha \text { rs } 361525 \text { was } \\
\text { significantly } \\
\text { associated with AKI }\end{array}$ & RIFLE \\
\hline $\begin{array}{l}\text { He, et al., } \\
\quad 2018\end{array}$ & $\begin{array}{l}\text { Retrospective } \\
\text { Case/Control } \\
\text { Study }\end{array}$ & Children with AKI & $\begin{array}{c}1138 \text { children with AKI } \\
\text { and } 1382 \text { non-AKI } \\
\text { controls. }\end{array}$ & 1138 Children & $\begin{array}{c}\text { TNF- } \alpha, \text { IL6, IL10, } \\
\text { IL18, NFKB1 and } \\
\text { NFKBIA }\end{array}$ & $\begin{array}{c}\text { NFKB1 rs28362491, } \\
\text { NFKBIA rs2233406 } \\
\text { and NFKBIA rs696 } \\
\text { were associated with } \\
\text { AKI in Children }\end{array}$ & pRIFLE \\
\hline $\begin{array}{c}\text { Aghakhani } \\
\text { Chegeni, et al., } \\
2018\end{array}$ & $\begin{array}{c}\text { Prospective Cohort } \\
\text { Study }\end{array}$ & $\begin{array}{c}\text { Iraninan patients } \\
\text { undergoing Cardiac } \\
\text { surgery }\end{array}$ & $\begin{array}{l}123 \text { Patients undergoing } \\
\text { CABG }\end{array}$ & 63 Patients & $\begin{array}{c}\text { STAT3 } \\
\text { polymorphism }\end{array}$ & $\begin{array}{c}\text { Rs1053004 GG } \\
\text { genotype } \\
\text { significantly } \\
\text { decreased CSA-AKI } \\
\text { risk }\end{array}$ & AKIN \\
\hline $\begin{array}{l}\text { Westphal, et al., } \\
2019\end{array}$ & $\begin{array}{l}\text { Prospective, } \\
\text { double-blind, } \\
\text { multicenter, } \\
\text { randomized trial } \\
\text { (RIPHeart) } \\
\text { GWAS. }\end{array}$ & $\begin{array}{c}\text { Myocardial } \\
\text { infarction, atrial } \\
\text { fibrillation, acute } \\
\text { stroke, acute kidney } \\
\text { injury and delirium } \\
\text { after cardiac surgery }\end{array}$ & $\begin{array}{l}1170 \text { patients of both } \\
\text { genders ( } 871 \text { males, } 299 \\
\text { females) undergoing } \\
\text { elective cardiac surgery }\end{array}$ & 52 Patients & 547,644 variants & $\begin{array}{c}\text { PHLPP2, BBS9, RyR2, } \\
\text { DUSP4 and HSPA8, } \\
\text { associated with new } \\
\text { onset of atrial } \\
\text { fibrillation, delirium, } \\
\text { myocardial } \\
\text { infarction, AKI and } \\
\text { stroke after cardiac } \\
\text { surgery. }\end{array}$ & - \\
\hline
\end{tabular}


Table 1. Cont.

\begin{tabular}{|c|c|c|c|c|c|c|c|}
\hline Study & Design & Clinical Settings & $\begin{array}{c}\text { Participants/Population } \\
\text { Characteristics }\end{array}$ & Patients with AKI & $\begin{array}{c}\text { Studied } \\
\text { Polymorphisms }\end{array}$ & Outcomes & AKI Definition \\
\hline $\begin{array}{l}\text { Vilander, et al., } \\
2019\end{array}$ & $\begin{array}{l}\text { Prospective, } \\
\text { observational } \\
\text { Finnish Acute } \\
\text { Kidney Injury } \\
\text { (FINNAKI) study }\end{array}$ & $\begin{array}{l}\text { Cohort of Finnish } \\
\text { critically ill patients }\end{array}$ & $\begin{array}{l}2647 \text { Critical ill patients } \\
\text { without chronic kidney } \\
\text { disease }\end{array}$ & 625 patients & $\begin{array}{c}\text { TNF- } \alpha \text { (rs1800629), } \\
\text { IL6 (rs1800796, } \\
\text { rs1800795, } \\
\text { rs10499563, } \\
\text { rs1474347, } \\
\text { rs13306435, } \\
\text { rs2069842 and } \\
\text { rs2069830), IL-8 } \\
\text { (rs4073), IL10 } \\
\text { (rs1800896), NOS3 } \\
\text { (rs2070744), NFKB1A } \\
\text { (rs1050851), AGT } \\
\text { (rs699 and rs2493133), } \\
\text { VEGFA (rs2010963 } \\
\text { and rs3025039), EPO } \\
\text { (rs1617640), SUFU } \\
\text { (rs10748825), HIF1- } \alpha \\
\text { (rs11549465), PNMT } \\
\text { (rs876493), MPO } \\
\text { (rs7208693), COMT } \\
\text { (rs4680), HSPB1 } \\
\text { (rs2868371), SP-D } \\
\text { (rs2243639 and } \\
\text { rs721917), HAMP } \\
\text { (rs10421768) and } \\
\text { BBS9 (rs10262995) } \\
\text { genes }\end{array}$ & $\begin{array}{l}\text { rs1800629 in TNF- } \alpha \text {; } \\
\text { and rs1800896 in } \\
\text { IL-10 were not } \\
\text { associated to AKI }\end{array}$ & KDIGO \\
\hline
\end{tabular}


Table 1. Cont.

\begin{tabular}{|c|c|c|c|c|c|c|c|}
\hline Study & Design & Clinical Settings & $\begin{array}{c}\text { Participants/Population } \\
\text { Characteristics }\end{array}$ & Patients with AKI & $\begin{array}{c}\text { Studied } \\
\text { Polymorphisms }\end{array}$ & Outcomes & AKI Definition \\
\hline $\begin{array}{l}\text { Averdunk, et al., } \\
2020\end{array}$ & $\begin{array}{l}\text { Prospective, } \\
\text { double-blind, } \\
\text { multicenter, } \\
\text { randomized trial } \\
\text { RIPHeart Study }\end{array}$ & CSA-AKI & $\begin{array}{l}1116 \text { patients undergoing } \\
\text { cardiac surgery }\end{array}$ & 170 Patients & $\begin{array}{c}\text { MIF CATT5-7 } \\
\text { (rs5844572/rs3063368, } \\
\text { “-794”) and G > C } \\
\text { single-nucleotide } \\
\text { polymorphism } \\
\text { (rs755622,-173) }\end{array}$ & $\begin{array}{c}\text { The MIF CATT7 } \\
\text { allele associates with } \\
\text { a higher risk of AKI } \\
\text { and death after } \\
\text { cardiac surgery }\end{array}$ & KDIGO \\
\hline
\end{tabular}

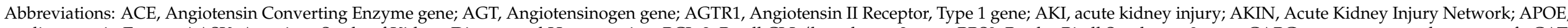

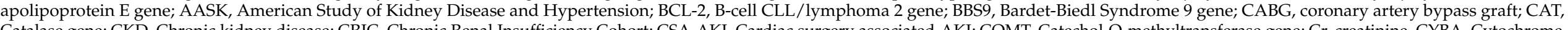

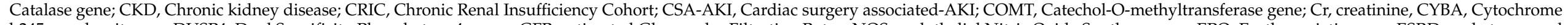

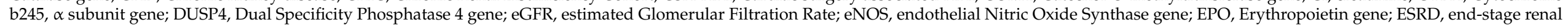

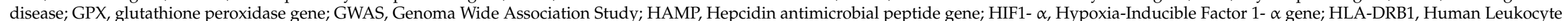

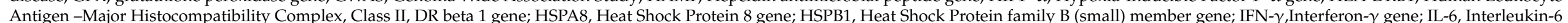

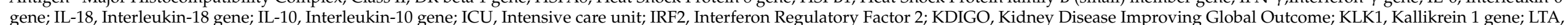

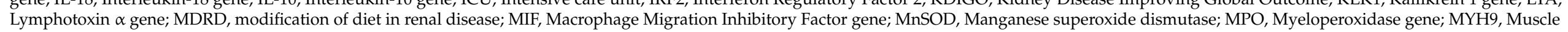

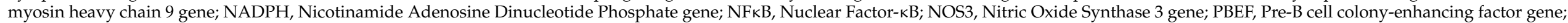

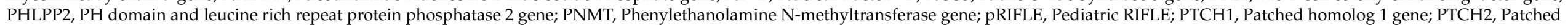

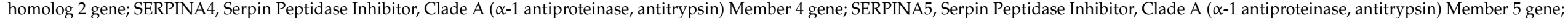

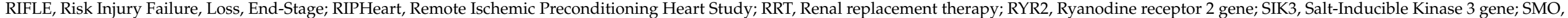

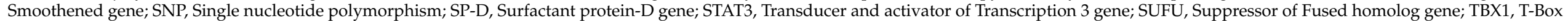
Transcription Factor 1 gene; TGF- $\beta$, Transient Growth Factor- $\beta$ gene; TNF- $\alpha$, Tumor Necrosis Factor $\alpha$ gene; US, United States; VEGF, Vascular Endothelial Growth Factor gene. 


\subsection{Controversy among Polymorphism Association Articles}

Polymorphism association studies usually consist of case-control and observational studies, comparing the occurrence of a genetic variation in some individuals with a certain illness to the occurrence in a control healthy population. Furthermore, although several polymorphisms have been identified, most studies often consist of relatively small homogeneous sample size populations, which significantly restricts the ability to draw conclusions from the results of the general population and frequently gives conflicting results with mainly nonsignificant findings. In general, the results are irregular and usually variable throughout the different analyses [36]. The deficiency of a reliable and consistent association is a serious limitation given the complicated, entangled pathogenesis of the disease. This basic understanding has barely contributed to creating a holistic view of the more susceptible phenotype prone to developing AKI. What is more, some diseases are polygenic in nature, and the interactions among relevant proposed genes have not been identified. Indeed, a far more complete overview could be the application of linking analyses, in which genetically related polymorphisms are studied and where the polymorphism of a particular gene could be the promoter of another illness-inducing variation [45].

Genome-wide association study (GWAS) has come to revolutionize the identification of novel disease susceptibility genes, leading to the discovery of novel biological mechanisms and offering insight into the ethnic variation of complex traits, among others. In spite of the fact that GWAS is a powerful method to determine genotype-phenotype association, this method presents limitations such as that it can only explain a small fraction of the heritability of complex traits and does not necessarily pinpoint causal variants and genes. Moreover, it was necessary to adopt a high level of significance to account for multiple tests. This is because false-positive relationships are innumerable in genetic association reports to identify frequent polymorphisms [46]. Moreover, the low frequency of some studied SNPs affects the power of these studies [47]. Thus, a considerably large sample size is needed to achieve the optimal statistical power and minimize the spurious associations [48,49].

Association of genetic polymorphisms and AKI risk usually differs among ethnicities, populations and geographical boundaries $[28,50,51]$. This is of paramount importance, as some genetic variations are uncommon in certain racial groups but not in others. Most article clinical settings refer to cardiac surgery patients, critically ill patients and contrastinduced AKI, which is the third most common cause of AKI.

Chang et al. found that patients with contrast-induced AKI presented a higher decline in kidney function than those without contrast media [52]. What is more, Wu and coworkers confirmed in 2018 that baseline serum creatinine is an independent risk factor for contrastinduced AKI [31]. Men with baseline creatinine $\geq 114.9 \mu \mathrm{mol} / \mathrm{L}$ and women with creatinine $\geq 88.4 \mu \mathrm{mol} / \mathrm{L}$ are at a higher risk of developing this injury [53].

Understanding the contribution of environmental and genetic determinants to develop a disease represents one of the most significant challenges that researchers currently face. This is because the phenotype is shaped by genomes, the environment and their interactions. So, the response of genotypes to the environment is different for complex traits and diseases. Several studies have attempted to quantify the contribution of genetic and environmental risk factors to diseases [54-56]. It has been estimated that the environmental contribution to the appearance of a certain condition ranges from $13 \%$ to $90 \%[57,58]$. Likewise, environmental factors can invoke heritable phenotype changes in DNA without alterations in its sequence. In this sense, epigenetics entails profound changes that affect gene activity and expression. Therefore, environmental determinants induce epigenetic marks that can trigger the development of certain illnesses.

\section{Associated Genes}

\subsection{Polymorphisms}

While an individual's genotype depicts the combination of parental genotypes, two distinct individuals have $>99.9 \%$ of their DNA sequences [59]. Variants observed in the left $0.1 \%$ of the human genome are known as gene polymorphisms and have become the 
topic of intense investigation. Indeed, such variations are markers of biological variety, and some genotypic polymorphisms have been identified to be related to particular human disease phenotypes [28]. It is unclear if any of these genetic polymorphisms are involved in the etiology of certain illnesses, as they may be placed close to other pathogenic genetic factors, known as linkage disequilibrium [28].

Variants can appear at one or more of the following locations: (1) the promoter region, (2) the exon(s) or the gene coding region, (3) the intron(s) or the gene intervening sequences and (4) the $3^{\prime}$-untranslated (3'-UTR) region (Figure 1).

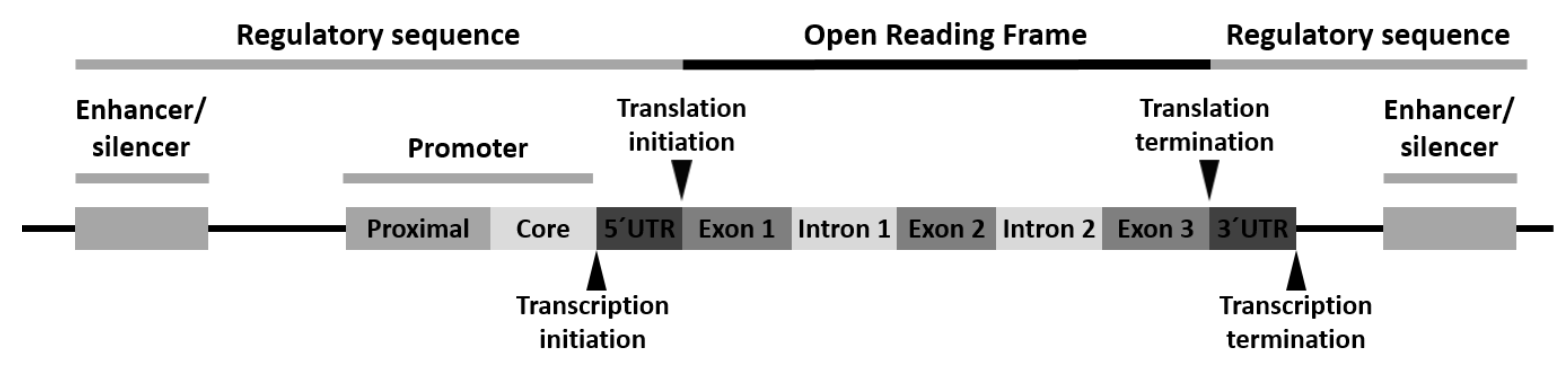

Figure 1. Schematic arrangement of a typical human gene with locations for gene polymorphism.

Polymorphism of the promoter region may affect the transcriptional activity. Polymorphism of the exons or encoding regions may be mute or affect gene expression or function. As introns are transcribed but removed from the messenger RNA (mRNA) before it is translated into a protein, its polymorphism may cause defects in RNA and mRNA processing. Finally, polymorphism in the $3^{\prime}$-UTR region may alter the RNA expectancy or influence the mRNA ribosomal translation [28].

Three classes of gene variants have been reported: (1) single-nucleotide polymorphism (SNP), (2) variable number of tandem repeats (VNTRs) or minisatellite polymorphism and (3) microsatellite polymorphism, with SNP being the most common [28].

AKI susceptibility and severity are related to multiple genetic factors that are involved in several pathophysiological mechanisms as follows.

\subsection{Systemic Inflammatory Response}

Given the relevance of inflammatory processes in the development of AKI, polymorphisms in inflammation-related genes might influence the predisposition of an individual to AKI [20].

Among the important inflammation-related genes that could play a role in AKI are IL6, IL10, NFBK1, NFKBIA, IL18 and TNF.

Even rare polymorphisms with very low minor allele frequencies could provide vital information and potential usefulness as a marker in the investigation of genetic predisposition to AKI [60].

\subsubsection{Interleukin 6 (IL6)}

IL6 encodes for interleukin-6, which has been shown to induce a cellular-mediated immune reaction that causes kidney damage [61]. Nevertheless, there are conflicting results regarding IL6's genetic polymorphism influence on AKI. While Dalboni et al. did not find any association between isolated or combined IL6 with other genetic polymorphisms and AKI development [62], Nechemia-Arbely et al. identified an association between IL6 and AKI development [63]. Furthermore, the plasma level of interleukin-6 has been found to serve as a biomarker for predicting AKI [64]. IL6-174 G/C polymorphism regulated postoperative IL6 levels and was related to the severity of postoperative AKI and length of hospital stay following coronary artery surgery [65]. Three promoter polymorphisms within the IL6 genes, namely rs1800795, rs1800796 and rs1800797 polymorphisms, have been identified to influence the expression and secretion of the cytokine [66]. Stafford-Smith 
et al. [67]. Found that a combination of angiotensinogen (AGT) gene $+842 \mathrm{C}$ allele (rs699) and IL-6-572C allele in Caucasians is related to kidney impairment.

\subsubsection{Interleukin 10 (IL 10)}

The IL-10 gene is located on chromosome 1q31-32 [68], and the variation in IL-10 production is genetically set up and controlled at the transcriptional region [28]. The IL-10 promoter site is polymorphic with a single-base-pair replacement at position -1082 (G to A).

IL10 encodes for interleukin-10, whose serum determination has also been associated with AKI $[69,70]$. Interleukin is implicated in AKI pathogenesis due to its anti-inflammatory role, as interleukin-10 facilitates the inhibition of immune cells and secretion of proinflammatory mediators, interrupting the healing process after kidney injury [70]. Promoter polymorphisms within the IL10 gene, namely rs1800896 and rs3021097 polymorphisms, have been demonstrated to influence the level of the interleukin [20]. Low-producing genotype AA of IL 10 polymorphism rs1800896 has been related to AKI [71], along with the combined genotype of rs1800629 GG + rs1800896 AA [62]. Similarly, Hashad and colleagues have demonstrated that the low-producer genotype of IL-10 (-1082 G/A) variants was a predisposing factor for AKI in ICU patients with severe sepsis.

\subsubsection{Tumor Necrosis Factor- $\alpha$ (TNF- $\alpha$ )}

The TNF- $\alpha$ gene is placed on the short arm of chromosome 6 . Variants located in the promoter region of the TNF- $\alpha$ gene at positions -238 ( $G$ to A) and -308 ( $G$ to $A$ ) have been described. The -308 A allele, known as the TNF- $\alpha 2$ allele, increases promoter activity, boosts TNF. $\alpha$ production and has been related to superior serum creatinine and urinary kidney injury molecule-1 (KIM-1) levels and greater multiorgan failure calculations in patients with AKI $[28,72]$.

TNF- $\alpha$ gene variants may alter variations in the proinflammatory cytokine reaction to stressful stimulation. This may have enormous implications in AKI presentation, as the intensity of proinflammatory reactions may determine the graveness of AKI and, therefore, the demand for renal replacement therapy and in-hospital mortality [28]. Figure 2 depicts an overview of the interstitial inflammation caused by TNF- $\alpha$.

The TNF- $\alpha$ gene rs1800629 identified by Jaber and colleagues [28] is one of the most frequently studied polymorphisms in AKI [62,71-76]. It is related to superior levels of TNF- $\alpha$ in vitro, AKI predisposition and increased mortality in patients with renal replacement therapy (RRT) [52]. While the TNF- $\alpha$ gene rs361525 has not been associated with AKI [43,77], Hashad et al. demonstrated rs1800629 polymorphism is a predisposing factor for AKI in ICU patients with severe sepsis [71].

2.2.4. Lymphotoxin $\alpha$ (LT- $\alpha$ ) or Transforming Growth Factor $\beta$ (TGF- $\beta$ ) and Interferon $\gamma$ $(\mathrm{IFN}-\gamma)$

IFN- $\gamma$ is related to inflammatory response and renal damage [78]. Similarly, LT- $\alpha$ or TGF- $\beta$ prompts neutrophils, T cells, monocytes and fibroblasts chemotaxis to the injury site [79]. Grabulosa and coworkers have shown that, although higher frequencies of polymorphisms of rs1800470, rs1800471 from the TGF- $\beta$ and rs2430561 from IFN- $\gamma$ were observed in critically ill patients, none was significantly associated as a risk factor for AKI [80]. 


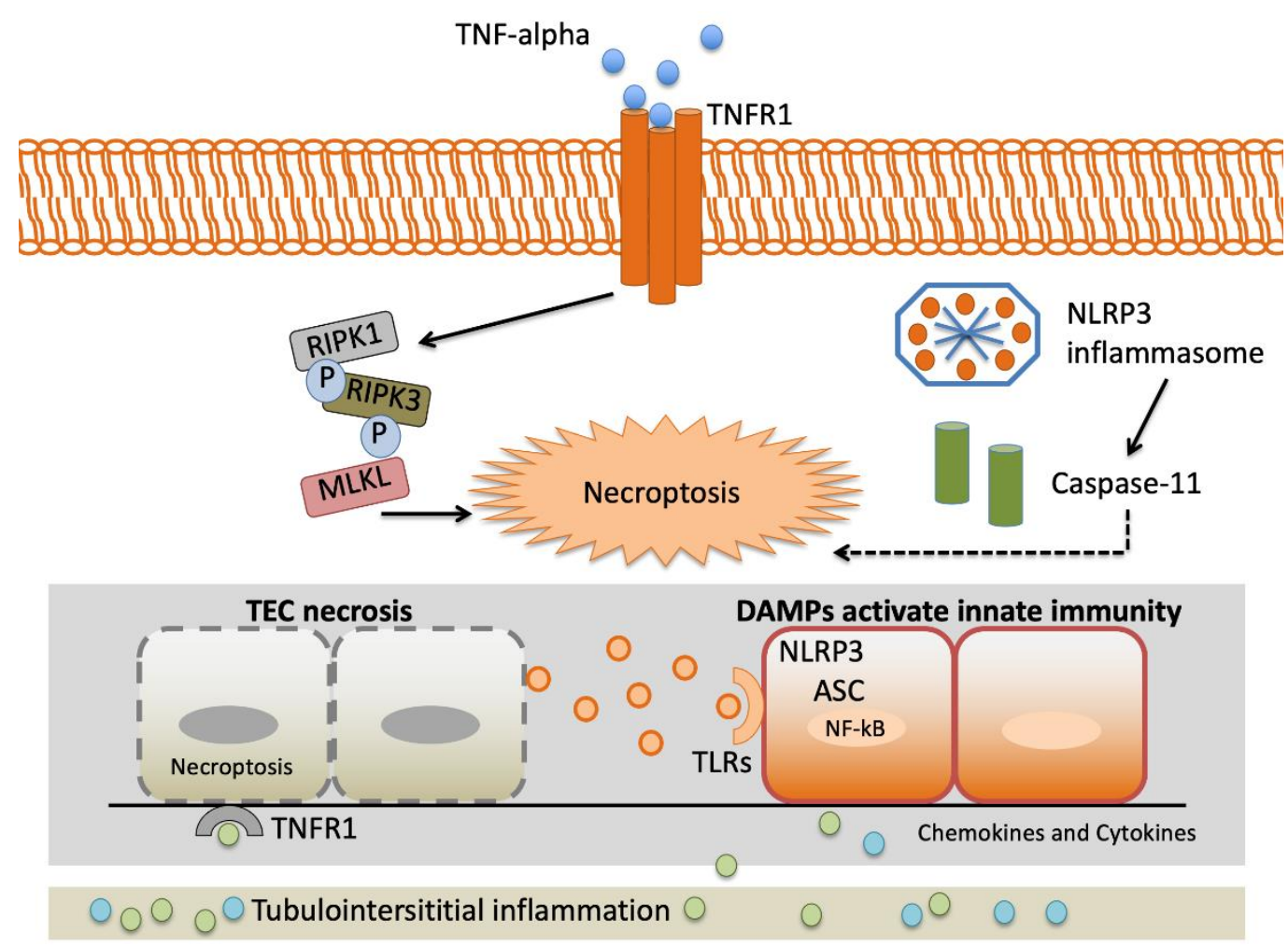

Figure 2. Landscape of interstitial inflammation caused by TNF- $\alpha$. Complexity of the TNF- $\alpha$ signaling system. TNFR1 signaling results in both activation of proinflammatory pathways and necroptosis triggered by the RIPK3-MLKL system. The NLRP3 inflammasome is a crucial element of the innate immune system that favors caspase activation and the production of proinflammatory cytokines due to damage-associated molecular patterns (DAMPs). Abbreviations: Apoptosis-associated speck-like protein containing a caspase recruitment domain (ASC). Damage-associated molecular patterns (DAMPs). Leucine-rich repeat-containing protein 3 (NLRP3). Mixed-lineage kinase domain-like (MLKL). Nuclear factor-kappa lightchain enhancer of activated B cells (NF- $\mathrm{kB}$ ). Receptor interacting protein kinase-1 (RIPK1). Receptor interacting protein kinase-3 (RIPK3). Tubular epithelial cell (TEC). TNF receptor 1 (TNFR1). Toll-like receptor (TLR).

\subsubsection{Human Leukocyte Antigen-Major Histocompatibility Complex, DR,} B1 (HLA-DRB1)

HLA-DR is a major histocompatibility complex (MHC) class II cell receptor encoded on chromosome 6 region 6p21.31 [81]. It serves as a ligand for the T-cell receptor (TCR) and is involved in multiple autoimmune conditions. In addition, HLA-DR expression is an integral part of the glomerular capillary and peritubular endothelium [82]. In acute inflammation states, such as AKI, HLA-DR expression is exerted. Nevertheless, HLA-DRB alleles were found to be associated with less requirement of RRT [83].

\subsubsection{Nuclear Factor Kappa Beta 1 (NFKB1)}

NFKB1 encodes for nuclear factor kappa beta 1 (NF-kB1), which is the most important member of the NF-kB family. Although it does not play a direct role in inflammation, it serves as the central regulator of a huge number of molecules involved in the inflammatory process. NF- $\mathrm{kB} 1$ functions as a central regulator for the activation and coordination of a vast assembling of genes involved in pro- and anti-inflammatory processes, including but not restricted to TNF, IL-1 $\beta$ and IL-6 [84]. NF- $k$ B1 participates in the inflammation process via various signaling pathways; therefore, its related genes are intimately connected with the AKI pathogenesis [85-88].

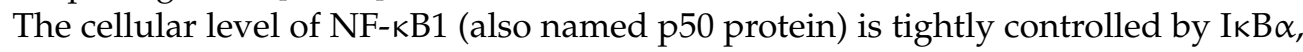
which is encoded by NFKBIA [89]. The rs2233406 and rs696 polymorphisms of the NF-BIA gene are, respectively, placed at the promoter and $3^{\prime}$ UTR region of the gene. 
NFKB1 rs28362491, NFKBIA rs2233406 and NFKBIA rs696 polymorphisms were related to reduced predisposition of AKI among Chinese children [20]. The NFKB1 rs28362491 polymorphism is an insertion/deletion variation of the gene. This insertion decreases the binding affinity of the promoter sequence and leads to a reduced NFKB1 promoter activity, which results in a low inflammation activity. NFKBIA rs2233406 polymorphism, however, occurs at the promoter region, and the variant T allele may disrupt the GATA-2 transcription factor binding, leading to a decreased transcriptional activity of the gene [89]. Conversely, the variant $G$ allele of the NFKBIA rs696 polymorphism can enhance the gene transcription by reducing the binding affinity of miR-449a microRNA on the gene. This exemplifies the complexity of the interactions by which genetic polymorphisms could affect disease susceptibility.

\subsubsection{Macrophage Migration Inhibitory Factor (MIF)}

Macrophage migration inhibitory factor (MIF) is a cytokine implicated in various inflammatory processes that is rapidly released from preformed intracellular pools in response to multiple cellular and systemic noxious stimuli, including ischemia/reperfusion, endotoxemia and surgery. For instance, cardiac surgery generates an increase in MIF serum levels [90].

Averdunk et al. showed that macrophage migration inhibitory factor (MIF) promoter polymorphisms (rs3063368, rs755622) are associated with AKI and death after cardiac surgery [91]. MIF may mediate AKI via CD74/TLR4-NF-KB pathway [92].

\subsubsection{Interleukin-18 (IL-18)}

Interleukin-18, encoded by IL18, is also implicated in AKI pathogenesis. Studies have shown that interleukin-18 is linked to AKI, inducing kidney acute tubular necrosis [93,94]. Thus, a disrupted level of interleukin-18 could serve as a risk factor for AKI. Promoter polymorphisms in the IL18 gene may influence the level of the cytokine. Two such IL18 polymorphisms are the rs1946518 and rs187238 polymorphisms.

\subsection{Vascular Hemodynamic Response}

\subsubsection{Vascular Endothelial Growth Factor (VEGF)}

Vascular endothelial growth factor (VEGF) is a protein that promotes angiogenesis, vessel permeability, cellular survival and differentiation $[95,96]$. The rs3025039 genotype has been shown to boost AKI predisposition in critically ill patients with severe sepsis [73].

\subsubsection{Angiotensinogen (AGT) and Angiotensin-Converting Enzyme (ACE)}

The AGT gene is located on chromosome 1 band q42. It encodes the angiotensinogen precursor, which is a fundamental component of the renin-angiotensin-aldosterone system (RAAS), being a potent vasoconstrictor. It is a major regulator of blood pressure, fluid and electrolyte homeostasis, playing a key role in renal disease pathology (Figure 3). While AGT $842 \mathrm{C}$ was identified by Stafford-Smith [67] as a major risk factor to develop postoperative renal injury, Isbir et al. [97]. Found that AGT receptor 1 (AGTR1) does not have a single relationship with AKI.

On the other hand, the angiotensin-converting enzyme (ACE) gene is placed on chromosome 17 band q23. Several studies have analyzed ACE insertion/deletion (I/D) polymorphism (rs4646994) [98-101]. Isbir and coworkers [97] found a relationship between the ACE D allele and an augmented susceptibility of postoperative AKI after coronary artery bypass graft surgery. Conversely, du Cheyron and colleagues [100] identified that I/I genotype is related to a higher vulnerability to AKI and RRT. 


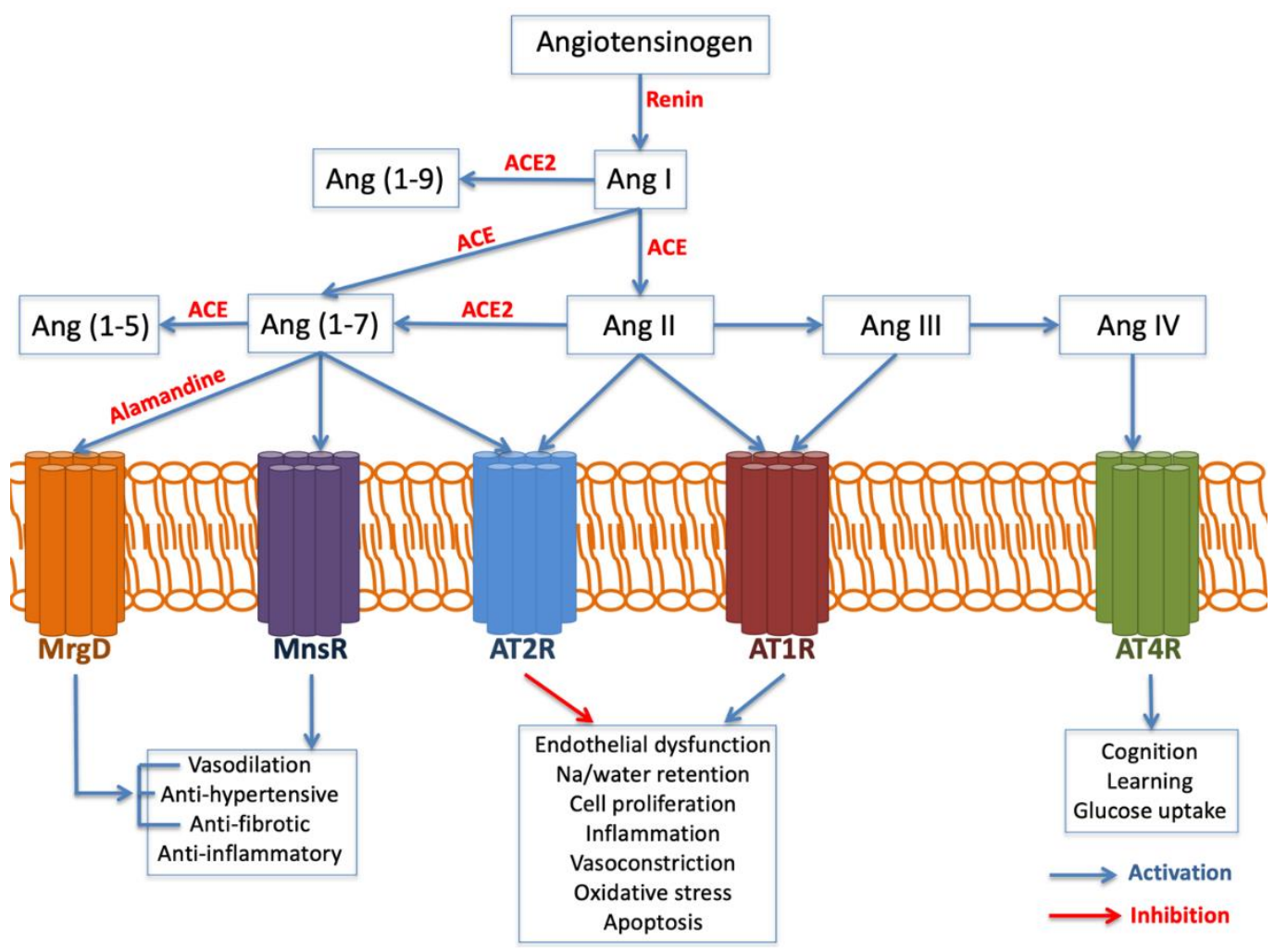

Figure 3. Angiotensin generated by angiotensin-converting enzyme (ACE) exerts inflammation, oxidative stress, apoptosis and fibrosis. Angiotensin II, through AT1R, is a prominent activator of endothelial dysfunction, cell proliferation, inflammation, vasoconstriction and oxidative stress mediated by the NADPH oxidase complex, with the production of oxygen reactants, which contribute to the oxidative stress and inflammatory processes involved in kidney injury. Abbreviations: Angiotensin (Ag). Angiotensin receptor (ATR). Mas-related G-protein-coupled receptor type D (MrgD).

\subsubsection{Endothelial No Synthase (eNOS)}

eNOS is the principal responsible for the vascular generation of nitric oxide, hence its variants might play a crucial role in the pathogenesis of endothelial dysfunction. Popov et al. demonstrated that T-786C eNOS polymorphism may predispose renal dysfunction and increase the incidence of dialysis following cardiac surgery [102]. Likewise, Stafford and coworkers showed that $894 \mathrm{~T}$ eNOS polymorphism was associated with cardiac surgeryassociated AKI (CSA-AKI) in Caucasians, as this variant may increment vascular tone and contribute to medullary ischemia [67].

\subsection{Cellular Metabolic Homeostasis}

\subsubsection{Cytochrome $b_{245}$}

Cytochrome b245 is involved in phagocytosis. While the A allele of the rs8854 polymorphism in the Cytochrome b245 $\alpha$ subunit (CYBA) gene was associated with less renal replacement therapy and hospital death compared to the GG genotype, the haplotype A-A-G-G of polymorphisms rs4782390, rs4673, rs3794624 and rs8854 was related to a higher vulnerability to this outcome [103].

\subsubsection{Kallikrein-1 (KLK1)}

Kallikreins belong to a family of serine proteases with diverse physiological functions. Kallikrein-1 (KLK1), one of 15 kallikrein family members, is the principal kallikrein expressed in the kidney and is implicated in both renal function and blood pressure control via vasodilatory and natriuretic results [104].

KLK1 is encoded by the KLK1 gene, which is located on chromosome 19q13.3 [104]. Polymorphisms at the promoter region have been identified and associated with 
CKD $[105,106]$. Susantitaphong and colleagues found that the I and G alleles of the KLK1 promoter polymorphism were related to an increased risk for AKI severity, including a doubled increase in serum creatinine, oliguria and RRT [104].

\subsubsection{Nicotinamide Adenosine Dinucleotide Phosphate (NADPH)}

Perianayagam et al. [107] found that the rs 4673 variant in the gene that encodes the NADPH oxidase p22phox subunit at position +242 is related to RRT and death among patients with AKI.

\subsubsection{PH Domain and Leucine-Rich Repeat Protein Phosphatase 2 (PHLPP2)}

$\mathrm{PH}$ domain and leucine-rich repeat protein phosphatase 2 (PHLPP2) is a phosphatase essential for the control of PKC isoforms and Akt kinases [108,109]. Akt kinases, known as prosurvival kinases, regulate the equilibrium between cell survival and apoptosis, aside from proliferation and cellular quiescence. The rs78064607 polymorphism located in the PHLPP2 gene was the only SNP identified by Westphal et al. [110] in their genome-wide study with increased risk for AKI.

\subsection{Adrenergic Response}

AKI produces the synthesis and release of catecholaminergic hormones as a response to any acute physiologic stress. As such, this pathway may play a relevant role in the etiology, pathogenesis, evolution and outcome of the disease.

\subsubsection{Catechol-O-Methyltransferase Gene (COMT)}

The catechol-O-methyltransferase gene (COMT) encodes the COMT enzyme, which degrades catecholamines and contributes to vasodilatory shock and AKI [111]. Albert et al. and Haase-Flelitz et al. found that the low activity (L) rs4680 polymorphism or LL genotype is related to CSA-AKI, more furosemide administration and RRT [111,112]; however, this association was discarded by Kornet et al. [113] and Albert et al. [112].

\subsubsection{Phenylethanolamine N-Methyltransferase (PNMT)}

PNMT is the final product of the catecholaminergic pathway and converts noradrenaline to adrenaline. While the gene rs $5638+1543 \mathrm{G}$ allele is related to an augmented predisposition for AKI, and the genotype $+1543 \mathrm{G} / \mathrm{A}$ is related to oliguria, the PNMT rs876493-161 A allele is associated with diminished mortality and less circulatory collapse [114].

\subsection{Cell Proliferation and Differentiation}

\subsubsection{Glutamate Receptor Metabotropic 7 (GRM7) and LMCD1 Antisense RNA 1} (LMCD1-AS1)

GRM7 encodes a protein G-coupled receptor and is one of the group III metabotropic glutamate receptors, which are linked to the inhibition of the AMPc cascade. LMCD1-AS1 is a recognized oncogene and exerts a proliferation function.

The intergenic region GRM7 I LMCD-AS1 located at chromosome 3p21.6 was detected to be highly related to CSA-AKI by Stafford-Smith et al., although no direct functional role was currently attributed to this intergenic region [115]. Future studies are needed to confirm this finding.

\subsubsection{Salt-Inducible Kinase 3 (SIK3)}

The SIK family members, including SIK3, are serine/threonine kinases that belong to the AMP-activated protein kinase (AMPK) family $[116,117]$. As their activity is upregulated in various cancers, they might play a key role in tumor appearance and progression. Polymorphism rs625145 in the SIK3 gene was correlated to elevated risk for AKI in patients with septic shock [118]. 


\subsubsection{Suppressor of Fused Homolog (SUFU)}

Hedgehog signaling is one of the crucial regulators of cell differentiation and has been deeply studied in the context of cancer. It also plays a key role in immune activation and inflammation, and its expression is upregulated while damaged organs are being healed. A key negative regulator of this signaling process is the suppressor of fused homolog (SUFU).

The polymorphisms rs10786691, rs12414407, rs10748825 and rs7078511 in the SUFU gene have been associated with renal performance in ICU patients with Enterobacteriaceae sepsis [119].

\subsubsection{Transducer and Activator of Transcription 3}

Transducer and activator of transcription 3 (STAT3) is a controller of T-helper 17 (Th17 cells) differentiation and function. Furthermore, STAT3 regulates and responds to various cytokines, including IL-1 $\beta$, IL-10, IL-6, IL-8, IL-11, IL-17, IL-21 and IL-23 [120].

The STAT3 rs1053004 polymorphism was significantly related to a lower vulnerability of CSA-AKI in an older Iranian population [121].

\subsubsection{Erythropoietin (EPO)}

While no association with AKI was found, Popov identified that the EPO gene rs1617640 T/G-polymorphism TT genotype was related to a higher creatine phosphokinase$\mathrm{MB}$ (CPK-MB) and RRT requirement [122].

\subsubsection{Surfactant Protein-D (SP-D)}

The SP-D gene is located in chromosome 10q22.2-q23.1 and is expressed in kidney tubules $[123,124]$. Liu et al. [125] demonstrated that patients with SP-D-11Thr/Thr genotype were more prone to AKI compared to those with other SP-D genotypes in a Chinese population. They showed that the more severely damaged the renal epithelial cells, the more SP-D protein will escape into the bloodstream, explaining the relationship between SP-D levels and AKI severity. In fact, greater serum SP-D levels were related to adverse clinical outcomes, such as higher AKI stage, longer RRT and increased mortality [125].

\subsection{Lipid Metabolism}

\subsubsection{Adiponectin}

Adiponectin is a multifaceted cytokine that has a major role in the adjustment of energy metabolism and inflammatory response $[126,127]$. While initial reports informed that they are exclusively encountered in adipocytes [128], recent research has demonstrated that they are also produced by lymphocytes [129], macrophages and endothelial and epithelial cells [130]. Bloodstream adiponectin levels are higher in patients with chronic kidney disease (CKD), and elevated levels of adiponectin predict increased cardiovascular and all-cause mortality and CKD progression [131].

Jin et al. [132] showed that adiponectin plays a pivotal role in the pathogenesis of acute renal ischemia/reperfusion injury and may be a potential therapeutic target.

\subsubsection{Apolipoprotein E (APOE)}

Apolipoprotein $\mathrm{E}$ is a protein implicated in lipid homeostasis, tissue restoration and immune response. The gene is located on chromosome 19q13.2 [44]. The polymorphism rs7412 of apolipoprotein E (APOE) and the non-e4 allele of polymorphism rs429358 are related to a greater peak serum creatinine $[133,134]$ and an increased risk of postoperative AKI $[97,134]$.

\subsubsection{Apolipoprotein L1 (APOL1)}

Variations in apolipoprotein L1, encoded by the APOL1 gene, are predisposing factors for focal segmental glomerulosclerosis, chronic renal and end-stage renal disease in African Americans $[135,136]$, which may be related to renal blood flow impairment. 
IRF2 controls the expression of the kidney disease risk gene APOL1. Zhao and colleagues found that rs62341639 and rs62341657 polymorphism on chromosome 4 near the APOL1 regulator IRF2 and rs9617814 and rs10854554 polymorphism on chromosome 22 close to the acute kidney injury-related gene TBX1 were associated with AKI development but without genome-wide significance [137]. TBX1 is a T-box transcription factor implicated in embryonic renal development, which was associated with the stimulation of TGF- $\beta$ and with renal damage in a gentamicin-induced AKI study [138].

\subsection{Noxious Stimuli}

Hypoxia-Inducible Factor-1- $\alpha$

Hypoxia-inducible factor-1- $\alpha$ controls the cell response to hypoxic conditions. In 2009, Kolyada et al. [139] found that the T allele of the rs11549465 variant located on the transcription factor of the hypoxia-inducible factor-1alpha (HIF-1 $\alpha$ ) gene is associated with the increased need for RRT.

\subsection{Oxidative Stress}

\subsubsection{Myeloperoxidase (MPO)}

Myeloperoxidase is a lysosomal enzyme involved in oxidative stress and helps granulocytes destroy pathogens. In 2012, Perianayagam found that rs2243828, rs2071409, (rs2759) and rs7208693 polymorphisms of the MPO gene were associated with lower urine output, more dialysis requirement and higher in-hospital mortality [140].

\subsubsection{Catalase}

Oxidative stress plays a major role in the pathogenesis of multiple conditions, and AKI is not an exception. The balance between the formation of reactive oxygen species and antioxidants is determinant. The $\mathrm{T}$ allele of the rs769217 variant of the antioxidant defense enzyme catalase (CAT) gene was associated with hospital morbidity and death among AKI patients in a Turkish population [141].

\subsection{Cell Survival and Apoptosis}

\subsubsection{B-Cell CLL/Lymphoma 2 (BCL2)}

BCL2 has a major part in apoptosis signaling as an antiapoptosis protein [142]. Carriers having the minor alleles of rs8094315 and rs12457893 polymorphism on BCL2 had a declined predisposition for developing AKI [118].

\subsubsection{Serpin Peptidase Inhibitor (SERPIN)}

SERPIN clade A (alpha-1 antiproteinase, antitrypsin) member 4 (SERPINA4) gene encodes kallistatin, which has vasodilatory, antioxidant, anti-inflammatory, and antiapoptotic properties [143]. Kallistatin suppresses TNF- $\alpha$ induced-apoptosis in in vitro endothelial cells [144]. Thus, polymorphism rs2093266 in the SERPINA4 gene was found to protect patients with septic shock against AKI [118].

\subsection{Cytoskeleton}

\section{Bardet-Biedl Syndrome 9 BBS9}

Bardet-Biedl syndrome 9 (BBS9) gene plays a fundamental role in the control of cilia length through the adjustment of actin cytoskeleton polymerization [145]. Stafford-Smith and colleagues [115] in their GWAS identified a relationship of polymorphism rs10262995 in BBS9 with CSA-AKI. Nevertheless, Vilander et al. did not find this association [47].

The association between gene studies and AKI susceptibility is depicted in Figure 4. 


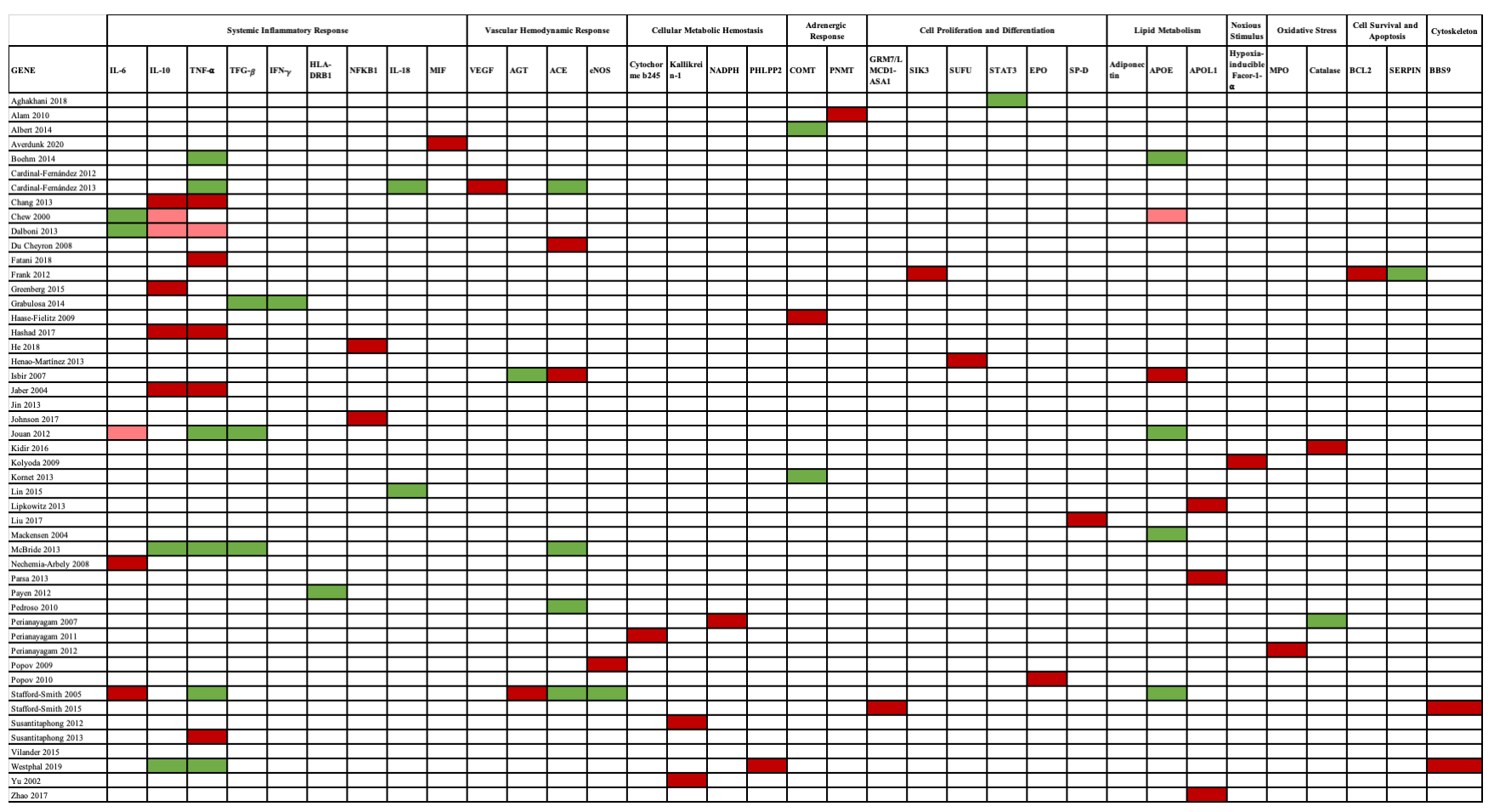

Figure 4. Genes and AKI susceptibility relationship. A red color pinpoints the genes associated with AKI, in which a dark red color highlights a strong association, while a light red color indicates a weak association. No association is marked by a green color. Genes are presented according to the mechanism involved in AKI pathogenesis. Abbreviations: ACE, angiotensin-converting enzyme gene; AGT, angiotensinogen gene; APOE, apolipoprotein E gene; BCL-2, B-cell CLL/lymphoma 2 gene; BBS9, Bardet-Biedl syndrome 9 gene; CAT, catalase gene; COMT, catechol-O-methyltransferase gene; eNOS, endothelial nitric oxide synthase gene; EPO, erythropoietin gene; HIF1- $\alpha$, hypoxia-inducible factor 1- $\alpha$ gene; HLA-DRB1, human leukocyte antigen-major histocompatibility complex, class II, DR beta 1 gene; IFN- $\gamma$, interferon- $\gamma$ gene; IL-6, interleukin-6 gene; IL-18, interleukin-18 gene; IL-10, interleukin-10 gene; MIF, macrophage migration inhibitory factor gene; MPO, myeloperoxidase gene; $\mathrm{NADPH}$, nicotinamide adenosine dinucleotide phosphate gene; $\mathrm{NF} \kappa \mathrm{B}$, nuclear factor- $\mathrm{KB}$ gene; PHLPP2, PH domain and leucine-rich repeat protein phosphatase 2 gene; PNMT, phenylethanolamine N-methyltransferase gene; SERPINA, serpin peptidase inhibitor, clade A ( $\alpha$-1 antiproteinase, antitrypsin) gene; SIK3, salt-inducible kinase 3 gene; SP-D, surfactant protein-D gene; STAT3, transducer and activator of transcription 3 gene; SUFU, suppressor of fused homolog gene; TGF- $\beta$, transient growth factor- $\beta$ gene; TNF- $\alpha$, tumor necrosis factor $\alpha$ gene; VEGF, vascular endothelial growth factor gene.

\section{Conclusions}

The overview of AKI pathogenesis suggests that various genes act collectively, generating either a favorable or harmful environment of pro- and anti-inflammatory cytokines, which determines the intensity of tissue damage. From the review, the most relevant genes are those related to the systemic inflammatory response, especially TNF- $\alpha$, which illustrates the huge impact that this process has on the etiology and pathophysiology intricacy of this disease. Genetic variants may influence the kidney response to an injury, deciding whether a patient moves towards a more serious condition or recovery. Thus, genetic variety provides a useful rational approach as clinical risk factors, unfolding partially of the global risk.

Examining the association between polymorphisms and AKI risk could potentially provide important insights into the disease. As it can help identify susceptible patients based on genotype patterns with the aim to prevent or ameliorate kidney damage. A further understanding of these genetic variants can serve to develop a substantial improvement to tackle this disease through the development of novel risk stratification scores and new genetic specific targets. For instance, even though novel biomarkers, such as neutrophil gelatinase-associated lipocalin (NGAL), KIM-1, tissue inhibitors of metalloproteinases 1 
(TIMP-1) and insulin-like growth factor binding protein 2 (IGFBP2), have been identified for the early detection and diagnosis of AKI. The relationship between the genetic variants of these markers with AKI predisposition has not been determined yet. This may be a wise approach to further tackle this disease. Thus, the knowledge of genetic determinants could benefit patient management as it can lend a hand to the creation of a genetic risk stratification tool with the development of genetic susceptibility biomarkers.

Author Contributions: Conceptualization C.O.-L., P.M.-P., E.T.; Investigation C.O.-L.; Project administration C.O.-L., Á.T.-V.; Supervision E.G.-M., F.J.L.-H., P.J.-M., E.T.; Writing-original draft C.O.-L., P.M.-P., P.J.-M.; Writing—review and editing C.O.-L., P.M.-P., P.J.-M. All authors have read and agreed to the published version of the manuscript.

Funding: This research received no external funding.

Institutional Review Board Statement: Not applicable.

Informed Consent Statement: Not applicable.

Data Availability Statement: Not applicable.

Conflicts of Interest: The authors declare no conflict of interest. Support was provided solely from institutional and/or departmental sources.

\section{References}

1. Kruzel-Davila, E.; Wasser, W.G.; Aviram, S.; Skorecki, K. APOL1 nephropathy: From gene to mechanisms of kidney injury. Nephrol. Dial. Transplant. 2016, 31, 349-358. [CrossRef]

2. Collins, A.J.; Foley, R.N.; Chavers, B.; Gilbertson, D.; Herzog, C.; Johansen, K.; Kasiske, B.; Kutner, N.; Liu, J.; St Peter, W.; et al. United States Renal Data System 2011 Annual Data Report: Atlas of chronic kidney disease \& end-stage renal disease in the United States. Am. J. Kidney Dis. 2012, 59, e1-e420. [CrossRef]

3. Grams, M.E.; Chow, E.K.; Segev, D.L.; Coresh, J. Lifetime incidence of CKD stages 3-5 in the United States. Am. J. Kidney Dis. 2013, 62, 245-252. [CrossRef] [PubMed]

4. Cartin-Ceba, R.; Haugen, E.N.; Iscimen, R.; Trillo-Alvarez, C.; Juncos, L.; Gajic, O. Evaluation of "Loss" and “End stage renal disease" after acute kidney injury defined by the Risk, Injury, Failure, Loss and ESRD classification in critically ill patients. Intensive Care Med. 2009, 35, 2087-2095. [CrossRef] [PubMed]

5. Ortega-Loubon, C.; Fernandez-Molina, M.; Fierro, I.; Jorge-Monjas, P.; Carrascal, Y.; Gomez-Herreras, J.I.; Tamayo, E. Postoperative kidney oxygen saturation as a novel marker for acute kidney injury after adult cardiac surgery. J. Thorac. Cardiovasc. Surg. 2019, 157, 2340-2351. [CrossRef] [PubMed]

6. Monedero, P.; García-Fernández, N.; Pérez-Valdivieso, J.R.; Vives, M.; Lavilla, J. Insuficiencia renal aguda. Rev. Esp. Anestesiol. Reanim. 2011, 58, 365-374. [CrossRef]

7. Aguado-Fraile, E.; Ramos, E.; Conde, E.; Rodriguez, M.; Martin-Gomez, L.; Lietor, A.; Candela, A.; Ponte, B.; Liano, F.; GarciaBermejo, M.L. A Pilot Study Identifying a Set of microRNAs As Precise Diagnostic Biomarkers of Acute Kidney Injury. PLoS ONE 2015, 10, e0127175. [CrossRef]

8. Ortega-Loubon, C.; Fernandez-Molina, M.; Carrascal-Hinojal, Y.; Fulquet-Carreras, E. Cardiac surgery-associated acute kidney injury. Ann. Card. Anaesth. 2016, 19, 687-698. [CrossRef]

9. Hoste, E.A.; Bagshaw, S.M.; Bellomo, R.; Cely, C.M.; Colman, R.; Cruz, D.N.; Edipidis, K.; Forni, L.G.; Gomersall, C.D.; Govil, D.; et al. Epidemiology of acute kidney injury in critically ill patients: The multinational AKI-EPI study. Intensive Care Med. 2015, 41, 1411-1423. [CrossRef]

10. Larach, D.B.; Engoren, M.C.; Schmidt, E.M.; Heung, M. Genetic variants and acute kidney injury: A review of the literature. J. Crit. Care 2018, 44, 203-211. [CrossRef]

11. Zou, Y.F.; Zhang, W. Role of microRNA in the detection, progression, and intervention of acute kidney injury. Exp. Biol. Med. 2018, 243, 129-136. [CrossRef] [PubMed]

12. Wang, H.E.; Muntner, P.; Chertow, G.M.; Warnock, D.G. Acute kidney injury and mortality in hospitalized patients. Am. J. Nephrol. 2012, 35, 349-355. [CrossRef] [PubMed]

13. Davies, H.; Leslie, G. Acute kidney injury and the critically ill patient. Dimens. Crit. Care Nurs. 2012, 31, 135-152. [CrossRef] [PubMed]

14. Lafrance, J.P.; Miller, D.R. Acute kidney injury associates with increased long-term mortality. J. Am. Soc. Nephrol. 2010, 21, 345-352. [CrossRef]

15. Vilander, L.M.; Kaunisto, M.A.; Pettila, V. Genetic predisposition to acute kidney injury-A systematic review. BMC Nephrol. 2015, 16, 197. [CrossRef]

16. Uchino, S.; Kellum, J.A.; Bellomo, R.; Doig, G.S.; Morimatsu, H.; Morgera, S.; Schetz, M.; Tan, I.; Bouman, C.; Macedo, E.; et al. Acute renal failure in critically ill patients: A multinational, multicenter study. JAMA 2005, 294, 813-818. [CrossRef] 
17. Tang, X.; Chen, D.; Yu, S.; Yang, L.; Mei, C.; Consortium, I.A.b.C. Acute kidney injury burden in different clinical units: Data from nationwide survey in China. PLoS ONE 2017, 12, e0171202. [CrossRef] [PubMed]

18. Gumbert, S.D.; Kork, F.; Jackson, M.L.; Vanga, N.; Ghebremichael, S.J.; Wang, C.Y.; Eltzschig, H.K. Perioperative Acute Kidney Injury. Anesthesiology 2019. [CrossRef]

19. Ronco, C.; Bellomo, R.; Kellum, J.A. Acute kidney injury. Lancet 2019, 394, 1949-1964. [CrossRef]

20. He, J.; Xie, G.; Wu, H.; Xu, S.; Xie, J.; Chen, Y.; Zhao, X. Association between inflammatory-response gene polymorphisms and risk of acute kidney injury in children. Biosci. Rep. 2018, 38. [CrossRef]

21. Fan, P.C.; Chen, C.C.; Chen, Y.C.; Chang, Y.S.; Chu, P.H. MicroRNAs in acute kidney injury. Hum. Genomics. 2016, 10, 29. [CrossRef]

22. McMahon, B.A.; Koyner, J.L.; Murray, P.T. Urinary glutathione S-transferases in the pathogenesis and diagnostic evaluation of acute kidney injury following cardiac surgery: A critical review. Curr. Opin. Crit. Care 2010, 16, 550-555. [CrossRef]

23. Matejovic, M.; Valesova, L.; Benes, J.; Sykora, R.; Hrstka, R.; Chvojka, J. Molecular differences in susceptibility of the kidney to sepsis-induced kidney injury. BMC Nephrol. 2017, 18, 183. [CrossRef] [PubMed]

24. Bonventre, J.V.; Yang, L. Cellular pathophysiology of ischemic acute kidney injury. J. Clin. Investig. 2011, 121, 4210-4221. [CrossRef] [PubMed]

25. Kinsey, G.R.; Li, L.; Okusa, M.D. Inflammation in acute kidney injury. Nephron Exp. Nephrol. 2008, 109, e102-e107. [CrossRef]

26. Wen, X.; Murugan, R.; Peng, Z.; Kellum, J.A. Pathophysiology of acute kidney injury: A new perspective. Contrib. Nephrol. 2010, 165, 39-45. [CrossRef]

27. Sharfuddin, A.A.; Molitoris, B.A. Pathophysiology of ischemic acute kidney injury. Nat. Rev. Nephrol. 2011, 7, 189-200. [CrossRef]

28. Jaber, B.L.; Liangos, O.; Pereira, B.J.; Balakrishnan, V.S. Polymorphism of immunomodulatory cytokine genes: Implications in acute renal failure. Blood Purif. 2004, 22, 101-111. [CrossRef] [PubMed]

29. Li, Y.F.; Jing, Y.; Hao, J.; Frankfort, N.C.; Zhou, X.; Shen, B.; Liu, X.; Wang, L.; Li, R. MicroRNA-21 in the pathogenesis of acute kidney injury. Protein Cell 2013, 4, 813-819. [CrossRef] [PubMed]

30. Akcay, A.; Nguyen, Q.; Edelstein, C.L. Mediators of inflammation in acute kidney injury. Mediat. Inflamm. 2009, $2009,137072$. [CrossRef] [PubMed]

31. Wu, R.; Kong, Y.; Yin, J.; Liang, R.; Lu, Z.; Wang, N.; Zhao, Q.; Zhou, Y.; Yan, C.; Wang, F.; et al. Antithrombin is a Novel Predictor for Contrast Induced Nephropathy After Coronary Angiography. Kidney Blood Press Res. 2018, 43, 170-180. [CrossRef] [PubMed]

32. Kong, Y.; Yin, J.; Cheng, D.; Lu, Z.; Wang, N.; Wang, F.; Liang, M. Antithrombin III Attenuates AKI Following Acute Severe Pancreatitis. Shock 2018, 49, 572-579. [CrossRef] [PubMed]

33. Wang, F.; Zhang, G.; Lu, Z.; Geurts, A.M.; Usa, K.; Jacob, H.J.; Cowley, A.W.; Wang, N.; Liang, M. Antithrombin III/SerpinC1 insufficiency exacerbates renal ischemia/reperfusion injury. Kidney Int. 2015, 88, 796-803. [CrossRef] [PubMed]

34. Garzotto, F.; Piccinni, P.; Cruz, D.; Gramaticopolo, S.; Dal Santo, M.; Aneloni, G.; Kim, J.C.; Rocco, M.; Alessandri, E.; Giunta, F.; et al. RIFLE-based data collection/management system applied to a prospective cohort multicenter Italian study on the epidemiology of acute kidney injury in the intensive care unit. Blood Purif. 2011, 31, 159-171. [CrossRef] [PubMed]

35. Bonventre, J.V.; Weinberg, J.M. Recent advances in the pathophysiology of ischemic acute renal failure. J. Am. Soc. Nephrol. 2003, 14, 2199-2210. [CrossRef]

36. Lu, J.C.; Coca, S.G.; Patel, U.D.; Cantley, L.; Parikh, C.R. Translational Research Investigating, Biomarkers, Endpoints for Acute Kidney Injury Consortium: Searching for genes that matter in acute kidney injury: A systematic review. Clin. J. Am. Soc. Nephrol. 2009, 4, 1020-1031. [CrossRef] [PubMed]

37. Cancer Genome Atlas Research Network; Weinstein, J.N.; Collisson, E.A.; Mills, G.B.; Shaw, K.R.; Ozenberger, B.A.; Ellrott, K.; Shmulevich, I.; Sander, C.; Stuart, J.M. The Cancer Genome Atlas Pan-Cancer analysis project. Nat. Genet. 2013, 45, 1113-1120. [CrossRef]

38. Barretina, J.; Caponigro, G.; Stransky, N.; Venkatesan, K.; Margolin, A.A.; Kim, S.; Wilson, C.J.; Lehar, J.; Kryukov, G.V.; Sonkin, D.; et al. The Cancer Cell Line Encyclopedia enables predictive modelling of anticancer drug sensitivity. Nature 2012, 483, 603-607. [CrossRef]

39. Garnett, M.J.; Edelman, E.J.; Heidorn, S.J.; Greenman, C.D.; Dastur, A.; Lau, K.W.; Greninger, P.; Thompson, I.R.; Luo, X.; Soares, J.; et al. Systematic identification of genomic markers of drug sensitivity in cancer cells. Nature 2012, 483, 570-575. [CrossRef]

40. Zibar, L.; Wagner, J.; Pavlinic, D.; Galic, J.; Pasini, J.; Juras, K.; Barbic, J. The relationship between interferon-gamma gene polymorphism and acute kidney allograft rejection. Scand. J. Immunol. 2011, 73, 319-324. [CrossRef]

41. Karimi, M.H.; Daneshmandi, S.; Pourfathollah, A.A.; Geramizadeh, B.; Yaghobi, R.; Rais-Jalali, G.A.; Roozbeh, J.; Bolandparvaz, S. A study of the impact of cytokine gene polymorphism in acute rejection of renal transplant recipients. Mol. Biol. Rep. 2012, 39, 509-515. [CrossRef] [PubMed]

42. Lazar, A.; Georgescu, A.M.; Vitin, A.; Azamfirei, L. Precision Medicine and its Role in the Treatment of Sepsis: A Personalised View. J. Crit. Care Med. 2019, 5, 90-96. [CrossRef] [PubMed]

43. Cardinal-Fernandez, P.; Ferruelo, A.; Martin-Pellicer, A.; Nin, N.; Esteban, A.; Lorente, J.A. Genetic determinants of acute renal damage risk and prognosis: A systematic review. Med. Intensiva 2012, 36, 626-633. [CrossRef]

44. Haase-Fielitz, A.; Haase, M.; Bellomo, R.; Dragun, D. Genetic polymorphisms in sepsis- and cardiopulmonary bypass-associated acute kidney injury. Contrib. Nephrol. 2007, 156, 75-91. [CrossRef]

45. Nabel, E.G. Cardiovascular disease. N. Engl. J. Med. 2003, 349, 60-72. [CrossRef] [PubMed] 
46. Lohmueller, K.E.; Pearce, C.L.; Pike, M.; Lander, E.S.; Hirschhorn, J.N. Meta-analysis of genetic association studies supports a contribution of common variants to susceptibility to common disease. Nat. Genet. 2003, 33, 177-182. [CrossRef]

47. Vilander, L.M.; Vaara, S.T.; Kaunisto, M.A.; Pettila, V.; Study Group, T.F. Common Inflammation-Related Candidate Gene Variants and Acute Kidney Injury in 2647 Critically Ill Finnish Patients. J. Clin. Med. 2019, 8, 342. [CrossRef]

48. Tam, V.; Patel, N.; Turcotte, M.; Bosse, Y.; Pare, G.; Meyre, D. Benefits and limitations of genome-wide association studies. Nat. Rev. Genet. 2019, 20, 467-484. [CrossRef]

49. Korte, A.; Farlow, A. The advantages and limitations of trait analysis with GWAS: A review. Plant Methods 2013, 9, 29. [CrossRef]

50. Rosenberg, N.A.; Huang, L.; Jewett, E.M.; Szpiech, Z.A.; Jankovic, I.; Boehnke, M. Genome-wide association studies in diverse populations. Nat. Rev. Genet. 2010, 11, 356-366. [CrossRef]

51. Kraft, P.; Zeggini, E.; Ioannidis, J.P. Replication in genome-wide association studies. Stat. Sci. 2009, 24, 561-573. [CrossRef]

52. Chang, C.F.; Lu, T.M.; Yang, W.C.; Lin, S.J.; Lin, C.C.; Chung, M.Y. Gene polymorphisms of interleukin-10 and tumor necrosis factor-alpha are associated with contrast-induced nephropathy. Am. J. Nephrol. 2013, 37, 110-117. [CrossRef]

53. McCullough, P.A.; Stacul, F.; Becker, C.R.; Adam, A.; Lameire, N.; Tumlin, J.A.; Davidson, C.J.; CIN Consensus Working Panel. Contrast-Induced Nephropathy (CIN) Consensus Working Panel: Executive summary. Rev. Cardiovasc. Med. $2006,7,177-197$.

54. Caspi, A.; Sugden, K.; Moffitt, T.E.; Taylor, A.; Craig, I.W.; Harrington, H.; McClay, J.; Mill, J.; Martin, J.; Braithwaite, A.; et al. Influence of life stress on depression: Moderation by a polymorphism in the 5-HTT gene. Science 2003, 301, 386-389. [CrossRef]

55. Klimek, P.; Aichberger, S.; Thurner, S. Disentangling genetic and environmental risk factors for individual diseases from multiplex comorbidity networks. Sci. Rep. 2016, 6, 39658. [CrossRef]

56. Purcell, S. Variance components models for gene-environment interaction in twin analysis. Twin Res. 2002, 5, 554-571. [CrossRef]

57. Pruss-Ustun, A.; Wolf, J.; Corvalan, C.; Neville, T.; Bos, R.; Neira, M. Diseases due to unhealthy environments: An updated estimate of the global burden of disease attributable to environmental determinants of health. J. Public Health 2017, 39, 464-475. [CrossRef]

58. Rappaport, S.M.; Smith, M.T. Epidemiology. Environment and disease risks. Science 2010, 330, 460-461. [CrossRef]

59. Venter, J.C.; Adams, M.D.; Myers, E.W.; Li, P.W.; Mural, R.J.; Sutton, G.G.; Smith, H.O.; Yandell, M.; Evans, C.A.; Holt, R.A.; et al. The sequence of the human genome. Science 2001, 291, 1304-1351. [CrossRef]

60. Tabangin, M.E.; Woo, J.G.; Martin, L.J. The effect of minor allele frequency on the likelihood of obtaining false positives. BMC Proc. 2009, 3, S41. [CrossRef]

61. Su, H.; Lei, C.T.; Zhang, C. Interleukin-6 Signaling Pathway and Its Role in Kidney Disease: An Update. Front. Immunol. 2017, 8, 405. [CrossRef]

62. Dalboni, M.A.; Quinto, B.M.; Grabulosa, C.C.; Narciso, R.; Monte, J.C.; Durao, M., Jr.; Rizzo, L.; Cendoroglo, M.; Santos, O.P.; Batista, M.C. Tumour necrosis factor-alpha plus interleukin-10 low producer phenotype predicts acute kidney injury and death in intensive care unit patients. Clin. Exp. Immunol. 2013, 173, 242-249. [CrossRef]

63. Nechemia-Arbely, Y.; Barkan, D.; Pizov, G.; Shriki, A.; Rose-John, S.; Galun, E.; Axelrod, J.H. IL-6/IL-6R axis plays a critical role in acute kidney injury. J. Am. Soc. Nephrol. 2008, 19, 1106-1115. [CrossRef]

64. Gu, W.; Gurguis, C.I.; Zhou, J.J.; Zhu, Y.; Ko, E.A.; Ko, J.H.; Wang, T.; Zhou, T. Functional and Structural Consequence of Rare Exonic Single Nucleotide Polymorphisms: One Story, Two Tales. Genome Biol. Evol. 2015, 7, 2929-2940. [CrossRef]

65. Gaudino, M.; Di Castelnuovo, A.; Zamparelli, R.; Andreotti, F.; Burzotta, F.; Iacoviello, L.; Glieca, F.; Alessandrini, F.; Nasso, G.; Donati, M.B.; et al. Genetic control of postoperative systemic inflammatory reaction and pulmonary and renal complications after coronary artery surgery. J. Thorac. Cardiovasc. Surg. 2003, 126, 1107-1112. [CrossRef]

66. Kamarainen, O.P.; Solovieva, S.; Vehmas, T.; Luoma, K.; Riihimaki, H.; Ala-Kokko, L.; Mannikko, M.; Leino-Arjas, P. Common interleukin-6 promoter variants associate with the more severe forms of distal interphalangeal osteoarthritis. Arthritis Res. Ther. 2008, 10, R21. [CrossRef]

67. Stafford-Smith, M.; Podgoreanu, M.; Swaminathan, M.; Phillips-Bute, B.; Mathew, J.P.; Hauser, E.H.; Winn, M.P.; Milano, C.; Nielsen, D.M.; Smith, M.; et al. Association of genetic polymorphisms with risk of renal injury after coronary bypass graft surgery. Am. J. Kidney Dis. 2005, 45, 519-530. [CrossRef]

68. Omoyinmi, E.; Forabosco, P.; Hamaoui, R.; Bryant, A.; Hinks, A.; Ursu, S.; Wedderburn, L.R.; Thomson, W.; Lewis, C.M.; Woo, P.; et al. Association of the IL-10 gene family locus on chromosome 1 with juvenile idiopathic arthritis (JIA). PLoS ONE 2012, 7, e47673. [CrossRef]

69. Zhang, W.R.; Garg, A.X.; Coca, S.G.; Devereaux, P.J.; Eikelboom, J.; Kavsak, P.; McArthur, E.; Thiessen-Philbrook, H.; Shortt, C.; Shlipak, M.; et al. Plasma IL-6 and IL-10 Concentrations Predict AKI and Long-Term Mortality in Adults after Cardiac Surgery. J. Am. Soc. Nephrol. 2015, 26, 3123-3132. [CrossRef]

70. Greenberg, J.H.; Whitlock, R.; Zhang, W.R.; Thiessen-Philbrook, H.R.; Zappitelli, M.; Devarajan, P.; Eikelboom, J.; Kavsak, P.A.; Devereaux, P.J.; Shortt, C.; et al. Interleukin-6 and interleukin-10 as acute kidney injury biomarkers in pediatric cardiac surgery. Pediatr. Nephrol. 2015, 30, 1519-1527. [CrossRef]

71. Hashad, D.I.; Elsayed, E.T.; Helmy, T.A.; Elawady, S.M. Study of the role of tumor necrosis factor-alpha (-308 G/A) and interleukin$10(-1082 \mathrm{G} / \mathrm{A})$ polymorphisms as potential risk factors to acute kidney injury in patients with severe sepsis using high-resolution melting curve analysis. Ren. Fail. 2017, 39, 77-82. [CrossRef]

72. Susantitaphong, P.; Perianayagam, M.C.; Tighiouart, H.; Liangos, O.; Bonventre, J.V.; Jaber, B.L. Tumor necrosis factor alpha promoter polymorphism and severity of acute kidney injury. Nephron Clin. Pract. 2013, 123, 67-73. [CrossRef] [PubMed] 
73. Cardinal-Fernandez, P.; Ferruelo, A.; El-Assar, M.; Santiago, C.; Gomez-Gallego, F.; Martin-Pellicer, A.; Frutos-Vivar, F.; Penuelas, O.; Nin, N.; Esteban, A.; et al. Genetic predisposition to acute kidney injury induced by severe sepsis. J. Crit. Care 2013, 28, 365-370. [CrossRef]

74. Jouan, J.; Golmard, L.; Benhamouda, N.; Durrleman, N.; Golmard, J.L.; Ceccaldi, R.; Trinquart, L.; Fabiani, J.N.; Tartour, E.; Jeunemaitre, X.; et al. Gene polymorphisms and cytokine plasma levels as predictive factors of complications after cardiopulmonary bypass. J. Thorac. Cardiovasc. Surg. 2012, 144, 467-473. [CrossRef]

75. Boehm, J.; Eichhorn, S.; Kornek, M.; Hauner, K.; Prinzing, A.; Grammer, J.; Lahm, H.; Wagenpfeil, S.; Lange, R. Apolipoprotein E genotype, TNF-alpha 308G/A and risk for cardiac surgery associated-acute kidney injury in Caucasians. Ren. Fail. 2014, 36, 237-243. [CrossRef] [PubMed]

76. Manchanda, P.K.; Kumar, A.; Kaul, A.; Mittal, R.D. Correlation between a gene polymorphism of tumor necrosis factor-alpha (G/A) and end-stage renal disease: A pilot study from north India. Clin. Chim. Acta 2006, 370, 152-157. [CrossRef] [PubMed]

77. Fatani, S.H.; Al Refai, A.A.; Al-Amodi, H.S.; Kamel, H.F.; Al-Khatieb, K.; Bader, H. Assessment of tumor necrosis factor alpha polymorphism TNF-alpha-238 (rs 361525) as a risk factor for development of acute kidney injury in critically ill patients. Mol. Biol. Rep. 2018, 45, 839-847. [CrossRef]

78. Roedder, S.; Kimura, N.; Okamura, H.; Hsieh, S.C.; Gong, Y.; Sarwal, M.M. Significance and suppression of redundant IL17 responses in acute allograft rejection by bioinformatics based drug repositioning of fenofibrate. PLoS ONE 2013, 8, e56657. [CrossRef]

79. Keithi-Reddy, S.R.; Addabbo, F.; Patel, T.V.; Mittal, B.V.; Goligorsky, M.S.; Singh, A.K. Association of anemia and erythropoiesis stimulating agents with inflammatory biomarkers in chronic kidney disease. Kidney Int. 2008, 74, 782-790. [CrossRef]

80. Grabulosa, C.C.; Batista, M.C.; Cendoroglo, M.; Quinto, B.M.; Narciso, R.; Monte, J.C.; Durao, M.; Rizzo, L.V.; Santos, O.F.; Dalboni, M.A. Frequency of TGF- beta and IFN- gamma genotype as risk factors for acute kidney injury and death in intensive care unit patients. Biomed. Res. Int. 2014, 2014, 904730. [CrossRef]

81. Liu, B.; Shao, Y.; Fu, R. Current research status of HLA in immune-related diseases. Immun. Inflamm. Dis. 2021, 9, 340-350. [CrossRef]

82. Muczynski, K.A.; Cotner, T.; Anderson, S.K. Unusual expression of human lymphocyte antigen class II in normal renal microvascular endothelium. Kidney Int. 2001, 59, 488-497. [CrossRef]

83. Payen, D.; Lukaszewicz, A.C.; Legrand, M.; Gayat, E.; Faivre, V.; Megarbane, B.; Azoulay, E.; Fieux, F.; Charron, D.; Loiseau, P.; et al. A multicentre study of acute kidney injury in severe sepsis and septic shock: Association with inflammatory phenotype and HLA genotype. PLoS ONE 2012, 7, e35838. [CrossRef]

84. Liu, T.; Zhang, L.; Joo, D.; Sun, S.C. NF-kappaB signaling in inflammation. Signal Transduct. Target Ther. 2017, 2. [CrossRef]

85. Poveda, J.; Sanz, A.B.; Carrasco, S.; Ruiz-Ortega, M.; Cannata-Ortiz, P.; Sanchez-Nino, M.D.; Ortiz, A. Bcl3: A regulator of NF-kappaB inducible by TWEAK in acute kidney injury with anti-inflammatory and antiapoptotic properties in tubular cells. Exp. Mol. Med. 2017, 49, e352. [CrossRef]

86. Zhang, H.; Sun, S.C. NF-kappaB in inflammation and renal diseases. Cell Biosci. 2015, 5, 63. [CrossRef]

87. Song, N.; Thaiss, F.; Guo, L. NFkappaB and Kidney Injury. Front. Immunol. 2019, 10, 815. [CrossRef]

88. Johnson, F.L.; Patel, N.S.A.; Purvis, G.S.D.; Chiazza, F.; Chen, J.; Sordi, R.; Hache, G.; Merezhko, V.V.; Collino, M.; Yaqoob, M.M.; et al. Inhibition of IkappaB Kinase at 24 Hours After Acute Kidney Injury Improves Recovery of Renal Function and Attenuates Fibrosis. J. Am. Heart Assoc. 2017, 6, e005092. [CrossRef]

89. Tan, S.C.; Suzairi, M.S.; Aizat, A.A.; Aminudin, M.M.; Nurfatimah, M.S.; Bhavaraju, V.M.; Biswal, B.M.; Ankathil, R. Genderspecific association of NFKBIA promoter polymorphisms with the risk of sporadic colorectal cancer. Med. Oncol. $2013,30,693$. [CrossRef]

90. Stoppe, C.; Averdunk, L.; Goetzenich, A.; Soppert, J.; Marlier, A.; Kraemer, S.; Vieten, J.; Coburn, M.; Kowark, A.; Kim, B.S.; et al. The protective role of macrophage migration inhibitory factor in acute kidney injury after cardiac surgery. Sci. Transl. Med. 2018, 10. [CrossRef]

91. Averdunk, L.; Bernhagen, J.; Fehnle, K.; Surowy, H.; Ludecke, H.J.; Mucha, S.; Meybohm, P.; Wieczorek, D.; Leng, L.; Marx, G.; et al. The Macrophage Migration Inhibitory Factor (MIF) Promoter Polymorphisms (rs3063368, rs755622) Predict Acute Kidney Injury and Death after Cardiac Surgery. J. Clin. Med. 2020, 9, 2936. [CrossRef]

92. Li, J.H.; Tang, Y.; Lv, J.; Wang, X.H.; Yang, H.; Tang, P.M.K.; Huang, X.R.; He, Z.J.; Zhou, Z.J.; Huang, Q.Y.; et al. Macrophage migration inhibitory factor promotes renal injury induced by ischemic reperfusion. J. Cell. Mol. Med. 2019, 23, $3867-3877$. [CrossRef]

93. Awad, A.S.; El-Sharif, A.A. Curcumin immune-mediated and anti-apoptotic mechanisms protect against renal ischemia/reperfusion and distant organ induced injuries. Int. Immunopharmacol. 2011, 11, 992-996. [CrossRef] [PubMed]

94. Lin, X.; Yuan, J.; Zhao, Y.; Zha, Y. Urine interleukin-18 in prediction of acute kidney injury: A systemic review and meta-analysis. J. Nephrol. 2015, 28,7-16. [CrossRef]

95. Ferrara, N.; Gerber, H.P.; LeCouter, J. The biology of VEGF and its receptors. Nat. Med. 2003, 9, 669-676. [CrossRef]

96. Bates, D.O. Vascular endothelial growth factors and vascular permeability. Cardiovasc. Res. 2010, 87, 262-271. [CrossRef] [PubMed]

97. Isbir, S.C.; Tekeli, A.; Ergen, A.; Yilmaz, H.; Ak, K.; Civelek, A.; Zeybek, U.; Arsan, S. Genetic polymorphisms contribute to acute kidney injury after coronary artery bypass grafting. Heart Surg. Forum 2007, 10, E439-E444. [CrossRef] 
98. Clark, M.F.; Baudouin, S.V. A systematic review of the quality of genetic association studies in human sepsis. Intensive Care Med. 2006, 32, 1706-1712. [CrossRef] [PubMed]

99. Pedroso, J.A.; Paskulin, D.d.; Dias, F.S.; de França, E.; Alho, C.S. Temporal trends in acute renal dysfunction among critically ill patients according to I/D and -262A > T ACE polymorphisms. J. Bras. Nefrol. 2010, 32, 182-194. [CrossRef]

100. du Cheyron, D.; Fradin, S.; Ramakers, M.; Terzi, N.; Guillotin, D.; Bouchet, B.; Daubin, C.; Charbonneau, P. Angiotensin converting enzyme insertion/deletion genetic polymorphism: Its impact on renal function in critically ill patients. Crit. Care Med. 2008, 36, 3178-3183. [CrossRef]

101. McBride, W.T.; Prasad, P.S.; Armstrong, M.; Patterson, C.; Gilliland, H.; Drain, A.; Vuylsteke, A.; Latimer, R.; Khalil, N.; Evans, A.; et al. Cytokine phenotype, genotype, and renal outcomes at cardiac surgery. Cytokine 2013, 61, 275-284. [CrossRef]

102. Popov, A.F.; Hinz, J.; Schulz, E.G.; Schmitto, J.D.; Wiese, C.H.; Quintel, M.; Seipelt, R.; Schoendube, F.A. The eNOS 786C/T polymorphism in cardiac surgical patients with cardiopulmonary bypass is associated with renal dysfunction. Eur. J. Cardiothorac. Surg. 2009, 36, 651-656. [CrossRef]

103. Perianayagam, M.C.; Tighiouart, H.; Nievergelt, C.M.; O’Connor, D.T.; Liangos, O.; Jaber, B.L. CYBA Gene Polymorphisms and Adverse Outcomes in Acute Kidney Injury: A Prospective Cohort Study. Nephron Extra 2011, 1, 112-123. [CrossRef]

104. Susantitaphong, P.; Perianayagam, M.C.; Kang, S.W.; Zhang, W.; Rao, F.; O'Connor, D.T.; Jaber, B.L. Association of functional kallikrein-1 promoter polymorphisms and acute kidney injury: A case-control and longitudinal cohort study. Nephron Clin. Pract. 2012, 122, 107-113. [CrossRef]

105. Lee-Chen, G.J.; Liu, K.P.; Lai, Y.C.; Juang, H.S.; Huang, S.Y.; Lin, C.Y. Significance of the tissue kallikrein promoter and transforming growth factor-beta1 polymorphisms with renal progression in children with vesicoureteral reflux. Kidney Int. 2004, 65, 1467-1472. [CrossRef]

106. Yu, H.; Song, Q.; Freedman, B.I.; Chao, J.; Chao, L.; Rich, S.S.; Bowden, D.W. Association of the tissue kallikrein gene promoter with ESRD and hypertension. Kidney Int. 2002, 61, 1030-1039. [CrossRef]

107. Perianayagam, M.C.; Liangos, O.; Kolyada, A.Y.; Wald, R.; MacKinnon, R.W.; Li, L.; Rao, M.; Balakrishnan, V.S.; Bonventre, J.V.; Pereira, B.J.; et al. NADPH oxidase p22phox and catalase gene variants are associated with biomarkers of oxidative stress and adverse outcomes in acute renal failure. J. Am. Soc. Nephrol. 2007, 18, 255-263. [CrossRef]

108. Cai, J.; Fang, L.; Huang, Y.; Li, R.; Yuan, J.; Yang, Y.; Zhu, X.; Chen, B.; Wu, J.; Li, M. miR-205 targets PTEN and PHLPP2 to augment AKT signaling and drive malignant phenotypes in non-small cell lung cancer. Cancer Res. 2013, 73, 5402-5415. [CrossRef]

109. Xu, J.; Wang, Y.; Hua, X.; Xu, J.; Tian, Z.; Jin, H.; Li, J.; Wu, X.R.; Huang, C. Inhibition of PHLPP2/cyclin D1 protein translation contributes to the tumor suppressive effect of NFkappaB2 (p100). Oncotarget 2016, 7, 34112-34130. [CrossRef]

110. Westphal, S.; Stoppe, C.; Gruenewald, M.; Bein, B.; Renner, J.; Cremer, J.; Coburn, M.; Schaelte, G.; Boening, A.; Niemann, B.; et al. Genome-wide association study of myocardial infarction, atrial fibrillation, acute stroke, acute kidney injury and delirium after cardiac surgery-A sub-analysis of the RIPHeart-Study. BMC Cardiovasc. Disord. 2019, 19, 26. [CrossRef]

111. Haase-Fielitz, A.; Haase, M.; Bellomo, R.; Lambert, G.; Matalanis, G.; Story, D.; Doolan, L.; Buxton, B.; Gutteridge, G.; Luft, F.C.; et al. Decreased catecholamine degradation associates with shock and kidney injury after cardiac surgery. J. Am. Soc. Nephrol. 2009, 20, 1393-1403. [CrossRef]

112. Albert, C.; Kube, J.; Haase-Fielitz, A.; Dittrich, A.; Schanze, D.; Zenker, M.; Kuppe, H.; Hetzer, R.; Bellomo, R.; Mertens, P.R.; et al. Pilot study of association of catechol-O-methyl transferase rs4680 genotypes with acute kidney injury and tubular stress after open heart surgery. Biomark. Med. 2014, 8, 1227-1238. [CrossRef]

113. Kornek, M.; Deutsch, M.A.; Eichhorn, S.; Lahm, H.; Wagenpfeil, S.; Krane, M.; Lange, R.; Boehm, J. COMT-Val158Metpolymorphism is not a risk factor for acute kidney injury after cardiac surgery. Dis. Markers 2013, 35, 129-134. [CrossRef]

114. Alam, A.; O’Connor, D.T.; Perianayagam, M.C.; Kolyada, A.Y.; Chen, Y.; Rao, F.; Mahata, M.; Mahata, S.; Liangos, O.; Jaber, B.L. Phenylethanolamine $\mathrm{N}$-methyltransferase gene polymorphisms and adverse outcomes in acute kidney injury. Nephron Clin. Pract. 2010, 114, c253-c259. [CrossRef]

115. Stafford-Smith, M.; Li, Y.J.; Mathew, J.P.; Li, Y.W.; Ji, Y.; Phillips-Bute, B.G.; Milano, C.A.; Newman, M.F.; Kraus, W.E.; Kertai, M.D.; et al. Genome-wide association study of acute kidney injury after coronary bypass graft surgery identifies susceptibility loci. Kidney Int. 2015, 88, 823-832. [CrossRef]

116. Sun, Z.; Jiang, Q.; Li, J.; Guo, J. The potent roles of salt-inducible kinases (SIKs) in metabolic homeostasis and tumorigenesis. Signal Transduct. Target Ther. 2020, 5, 150. [CrossRef]

117. Taub, M.; Springate, J.E.; Cutuli, F. Targeting of renal proximal tubule Na,K-ATPase by salt-inducible kinase. Biochem. Biophys. Res. Commun. 2010, 393, 339-344. [CrossRef]

118. Frank, A.J.; Sheu, C.C.; Zhao, Y.; Chen, F.; Su, L.; Gong, M.N.; Bajwa, E.; Thompson, B.T.; Christiani, D.C. BCL2 genetic variants are associated with acute kidney injury in septic shock*. Crit. Care Med. 2012, 40, 2116-2123. [CrossRef]

119. Henao-Martinez, A.F.; Agler, A.H.; LaFlamme, D.; Schwartz, D.A.; Yang, I.V. Polymorphisms in the SUFU gene are associated with organ injury protection and sepsis severity in patients with Enterobacteriacea bacteremia. Infect. Genet. Evol. 2013, 16, 386-391. [CrossRef]

120. Yu, H.; Pardoll, D.; Jove, R. STATs in cancer inflammation and immunity: A leading role for STAT3. Nat. Rev. Cancer 2009, 9 , 798-809. [CrossRef] 
121. Aghakhani Chegeni, S.; Rahimzadeh, M.; Montazerghaem, H.; Khayatian, M.; Dasturian, F.; Naderi, N. Preliminary Report on the Association Between STAT3 Polymorphisms and Susceptibility to Acute Kidney Injury After Cardiopulmonary Bypass. Biochem. Genet 2018, 56, 627-638. [CrossRef]

122. Popov, A.F.; Schulz, E.G.; Schmitto, J.D.; Coskun, K.O.; Tzvetkov, M.V.; Kazmaier, S.; Zimmermann, J.; Schondube, F.A.; Quintel, M.; Hinz, J. Relation between renal dysfunction requiring renal replacement therapy and promoter polymorphism of the erythropoietin gene in cardiac surgery. Artif. Organs 2010, 34, 961-968. [CrossRef]

123. Di Angelo, S.; Lin, Z.; Wang, G.; Phillips, S.; Ramet, M.; Luo, J.; Floros, J. Novel, non-radioactive, simple and multiplex PCR-cRFLP methods for genotyping human SP-A and SP-D marker alleles. Dis. Markers 1999, 15, 269-281. [CrossRef]

124. Hu, F.; Ding, G.; Zhang, Z.; Gatto, L.A.; Hawgood, S.; Poulain, F.R.; Cooney, R.N.; Wang, G. Innate immunity of surfactant proteins A and D in urinary tract infection with uropathogenic Escherichia coli. Innate Immun. 2016, 22, 9-20. [CrossRef]

125. Liu, J.; Li, G.; Li, L.; Liu, Z.; Zhou, Q.; Wang, G.; Chen, D. Surfactant protein-D (SP-D) gene polymorphisms and serum level as predictors of susceptibility and prognosis of acute kidney injury in the Chinese population. BMC Nephrol. 2017, 18, 67. [CrossRef]

126. Tilg, H.; Moschen, A.R. Adipocytokines: Mediators linking adipose tissue, inflammation and immunity. Nat. Rev. Immunol. 2006, 6, 772-783. [CrossRef] [PubMed]

127. Karbowska, J.; Kochan, Z. Role of adiponectin in the regulation of carbohydrate and lipid metabolism. J. Physiol. Pharmacol. 2006, 57, 103-113.

128. Scherer, P.E.; Williams, S.; Fogliano, M.; Baldini, G.; Lodish, H.F. A novel serum protein similar to C1q, produced exclusively in adipocytes. J. Biol. Chem. 1995, 270, 26746-26749. [CrossRef] [PubMed]

129. Crawford, L.J.; Peake, R.; Price, S.; Morris, T.C.; Irvine, A.E. Adiponectin is produced by lymphocytes and is a negative regulator of granulopoiesis. J. Leukoc. Biol. 2010, 88, 807-811. [CrossRef]

130. Miller, M.; Cho, J.Y.; Pham, A.; Ramsdell, J.; Broide, D.H. Adiponectin and functional adiponectin receptor 1 are expressed by airway epithelial cells in chronic obstructive pulmonary disease. J. Immunol. 2009, 182, 684-691. [CrossRef]

131. Jorsal, A.; Tarnow, L.; Frystyk, J.; Lajer, M.; Flyvbjerg, A.; Parving, H.H.; Vionnet, N.; Rossing, P. Serum adiponectin predicts all-cause mortality and end stage renal disease in patients with type I diabetes and diabetic nephropathy. Kidney Int. 2008, 74, 649-654. [CrossRef]

132. Jin, X.; Chen, J.; Hu, Z.; Chan, L.; Wang, Y. Genetic deficiency of adiponectin protects against acute kidney injury. Kidney Int. 2013, 83, 604-614. [CrossRef]

133. MacKensen, G.B.; Swaminathan, M.; Ti, L.K.; Grocott, H.P.; Phillips-Bute, B.G.; Mathew, J.P.; Newman, M.F.; Milano, C.A.; Stafford-Smith, M.; Perioperative Outcomes Research, G.; et al. Preliminary report on the interaction of apolipoprotein E polymorphism with aortic atherosclerosis and acute nephropathy after CABG. Ann. Thorac. Surg. 2004, 78, 520-526. [CrossRef] [PubMed]

134. Chew, S.T.; Newman, M.F.; White, W.D.; Conlon, P.J.; Saunders, A.M.; Strittmatter, W.J.; Landolfo, K.; Grocott, H.P.; StaffordSmith, M. Preliminary report on the association of apolipoprotein E polymorphisms, with postoperative peak serum creatinine concentrations in cardiac surgical patients. Anesthesiology 2000, 93, 325-331. [CrossRef] [PubMed]

135. Lipkowitz, M.S.; Freedman, B.I.; Langefeld, C.D.; Comeau, M.E.; Bowden, D.W.; Kao, W.H.; Astor, B.C.; Bottinger, E.P.; Iyengar, S.K.; Klotman, P.E.; et al. Apolipoprotein L1 gene variants associate with hypertension-attributed nephropathy and the rate of kidney function decline in African Americans. Kidney Int. 2013, 83, 114-120. [CrossRef] [PubMed]

136. Parsa, A.; Kao, W.H.; Xie, D.; Astor, B.C.; Li, M.; Hsu, C.Y.; Feldman, H.I.; Parekh, R.S.; Kusek, J.W.; Greene, T.H.; et al. APOL1 risk variants, race, and progression of chronic kidney disease. N. Engl. J. Med. 2013, 369, 2183-2196. [CrossRef]

137. Zhao, B.; Lu, Q.; Cheng, Y.; Belcher, J.M.; Siew, E.D.; Leaf, D.E.; Body, S.C.; Fox, A.A.; Waikar, S.S.; Collard, C.D.; et al. A Genome-Wide Association Study to Identify Single-Nucleotide Polymorphisms for Acute Kidney Injury. Am. J. Respir. Crit. Care Med. 2017, 195, 482-490. [CrossRef]

138. Jiang, H.; Li, L.; Li-Ling, J.; Qiu, G.; Niu, Z.; Jiang, H.; Li, Y.; Huang, Y.; Sun, K. Increased Tbx1 expression may play a role via TGF $\beta$-Smad2/3 signaling pathway in acute kidney injury induced by gentamicin. Int. J. Clin. Exp. Pathol. 2014, 7, 1595-1605. [PubMed]

139. Kolyada, A.Y.; Tighiouart, H.; Perianayagam, M.C.; Liangos, O.; Madias, N.E.; Jaber, B.L. A genetic variant of hypoxia-inducible factor-1alpha is associated with adverse outcomes in acute kidney injury. Kidney Int. 2009, 75, 1322-1329. [CrossRef]

140. Perianayagam, M.C.; Tighiouart, H.; Liangos, O.; Kouznetsov, D.; Wald, R.; Rao, F.; O'Connor, D.T.; Jaber, B.L. Polymorphisms in the myeloperoxidase gene locus are associated with acute kidney injury-related outcomes. Kidney Int. 2012, 82, 909-919. [CrossRef] [PubMed]

141. Kidir, V.; Uz, E.; Yigit, A.; Altuntas, A.; Yigit, B.; Inal, S.; Uz, E.; Sezer, M.T.; Yilmaz, H.R. Manganese superoxide dismutase, glutathione peroxidase and catalase gene polymorphisms and clinical outcomes in acute kidney injury. Ren. Fail. 2016, 38, 372-377. [CrossRef] [PubMed]

142. Havasi, A.; Borkan, S.C. Apoptosis and acute kidney injury. Kidney Int. 2011, 80, 29-40. [CrossRef]

143. Yin, H.; Gao, L.; Shen, B.; Chao, L.; Chao, J. Kallistatin inhibits vascular inflammation by antagonizing tumor necrosis factoralpha-induced nuclear factor kappaB activation. Hypertension 2010, 56, 260-267. [CrossRef] 
144. Shen, B.; Gao, L.; Hsu, Y.T.; Bledsoe, G.; Hagiwara, M.; Chao, L.; Chao, J. Kallistatin attenuates endothelial apoptosis through inhibition of oxidative stress and activation of Akt-eNOS signaling. Am. J. Physiol. Heart Circ. Physiol. 2010, 299, H1419-H1427. [CrossRef]

145. Hernandez-Hernandez, V.; Pravincumar, P.; Diaz-Font, A.; May-Simera, H.; Jenkins, D.; Knight, M.; Beales, P.L. Bardet-Biedl syndrome proteins control the cilia length through regulation of actin polymerization. Hum. Mol. Genet. 2013, 22, 3858-3868. [CrossRef] 